Cooperative epistemic work in medical practice an analysis of physicians' clinical notes

Bansler, Jørgen P.; Havn, Erling Carl; Schmidt, Kjeld; Mønsted, Troels; Petersen, Helene Høgh; Svendsen, Jesper Hastrup

Published in:

Computer Supported Cooperative Work

DOI:

10.1007/s10606-016-9261-x

Publication date:

2016

Document version

Publisher's PDF, also known as Version of record

Document license:

CC BY

Citation for published version (APA):

Bansler, J. P., Havn, E. C., Schmidt, K., Mønsted, T., Petersen, H. H., \& Svendsen, J. H. (2016). Cooperative epistemic work in medical practice: an analysis of physicians' clinical notes. Computer Supported Cooperative Work, 25(6), 503-546. https://doi.org/10.1007/s10606-016-9261-x 


\title{
Cooperative Epistemic Work in Medical Practice: An Analysis of Physicians' Clinical Notes
}

\author{
Jørgen P. Bansler ${ }^{1}$, Erling C. Havn ${ }^{1}$, Kjeld Schmidt ${ }^{2,3}$, Troels Mønsted ${ }^{4}$, \\ Helen Høgh Petersen ${ }^{5} \&$ Jesper Hastrup Svendsen ${ }^{5}$ \\ ${ }^{1}$ University of Copenhagen, Copenhagen, Denmark (E-mail: bansler@diku.dk); ${ }^{2}$ Copenhagen \\ Business School, Frederiksberg, Denmark; ${ }^{3}$ University of Siegen, Siegen, Germany; ${ }^{4}$ University of \\ Oslo, Oslo , Norway; ${ }^{5}$ Rigshospitalet, Copenhagen , Denmark
}

\begin{abstract}
We examine an important part of the medical record that has not been studied extensively: physicians' clinical notes. These notes constitute an explanatory medical narrative that documents the patient's illness trajectory by combining each physician's notes into a common text. Although several prior CSCW studies have addressed the role of the medical record in patient care, they have not dealt specifically with the role, structure, and content of these notes. In this article, we present a detailed analysis of a set of physicians' clinical notes recording the acute hospitalization and subsequent treatment of a patient with chronic heart disease. We show that clinical notes are highly structured and conventionalized texts that promote conciseness while at the same time allowing physicians to express themselves in a precise and nuanced way. Based on this analysis, we argue that physicians' clinical notes form the core of the medical record. They serve both as a 'tool for thinking' for the individual physician, enabling him or her to make sense of the patient's past history and current condition, and as a coordinative artifact used by physicians, nurses, and other health care professionals. We conclude by discussing the implications of this research for the design of Electronic Medical Record (EMR) systems.
\end{abstract}

Keywords: Clinical documentation practices, Organisational communication genre, Clinical notes, Progress notes, Admission notes, Narratives, Medical discourse, Medical reasoning, Sensemaking, Medical record, Electronic health record, Electronic medical record

\section{Introduction}

The institution of the medical record is under increasing pressure from many different directions. Driven by advances in pharmaceutical, diagnostic, surgical, anesthetic, clinical, prosthetic, physiotherapeutic, and other technologies, the medical profession is undergoing a process of radical specialization ${ }^{1}$. At the same time, as a result of the very same advances in medical technologies people live longer and the percentage of patients with chronic diseases is consequently rising steadily (Strauss et al., 1985;

\footnotetext{
${ }^{1}$ Tentative and partial accounts of the research reported in this article have been published previously (e.g., Bansler et al., 2011, 2013b; Bansler et al., 2013a; Mønsted, 2015). The present article gives a significantly richer and more complete account of the case, and the analysis and discussion have been revised and extended.
} 
Parekh et al. 2010). The combined effect of these developments is that the medical record becomes bloated and fragmented: (a) the sheer volume and heterogeneity of the record increases with the repertoire of diagnostic and therapeutic technologies; (b) the medical record becomes partially replicated as chronic patients are in the care of increasingly specialized medical professionals; (c) the rising prevalence of multiple co-morbidities further exacerbates the growth and disintegration of the record, as many patients are being treated for multiple diseases at the same time (e.g., diabetes and heart disease). The result is that the effort and complexity of coordination increases and with that the risk of error (Hewett et al., 2009).

In response, governments and medical institutions are investing vast sums of money in Electronic Medical Record (EMR) systems ${ }^{2}$ to improve care, contain costs, boost efficiency, and drive collaboration between health care providers. EMR systems are seen as 'the backbone of all major international eHealth developments' (Car et al., 2008a), but so far results have been disappointing. While notable progress has been made with respect to administrative patient records (i.e., repositories of data for purposes of billing, resource allocation and utilization, capacity planning, and similar activities), when it comes to the integration of clinical documentation into the EMR unexpected difficulties have arisen (Greenhalgh et al., 2009; Rosenbloom et al. 2010). The implicit assumption that the medical record can be subjected to digitalization in much the same way as administrative records have been, has turned out to be quite naïve.

The difficulties and meager results so far have been thoroughly documented by two official reports from the US and the UK that both highlight 'the vast gap between the theoretical and empirically demonstrated benefits' of IT for health care (Car et al., 2008 b, p. 12). The first one is an extensive systematic literature review commissioned by the British NHS Connecting for Health Evaluation Programme. In their report, the researchers conclude that 'there is very limited rigorous evidence demonstrating that these technologies actually improve either the quality or safety of healthcare' (Car et al., 2008a, pp. xxv-xxvi). More specifically, they point out that 'the empirically demonstrated benefits relating to introduction of EHRs are currently limited to improved legibility, time savings for some professionals (nurses), and the facilitation of higher order functions such as audit, secondary analysis of routine data and performance management' (ibid., p. xix). A similar conclusion is reached in the second study, commissioned by the US National Library of Medicine ${ }^{3}$ and published by the National Research Council in 2009. In this study, an interdisciplinary group of experts conclude that EMR systems and similar IT applications for health care 'appear designed largely to automate tasks or business processes. They are often designed in ways that simply mimic existing paper-based forms and provide little

\footnotetext{
${ }^{2}$ Electronic Medical Record (EMR) systems are also often referred to as Electronic Patient Record (EPR) systems or Electronic Health Record (EHR) systems.

${ }^{3}$ The US National Library of Medicine was established in 1836 and is part of the National Institutes of Health $(\mathrm{NIH})$, which in turn is part of the US Department of Health and Human Services.
} 
support for the cognitive tasks of clinicians or the workflow of the people who must actually use the system' (Stead and Lin, 2009, pp. 3-4). As a result, 'the computer system frequently increases the workload [...] and can introduce new forms of error that are difficult to detect' (ibid., p. 17). It seems reasonable to conclude that while advances have been made in facilitating and automating certain 'higher order functions' and administrative tasks and although some progress may, of course, have been achieved since the publication of these reviews, relatively little has been accomplished when it comes to supporting the primary clinical work. ${ }^{4}$

\subsection{Clinical documentation practices}

How to incorporate clinical documentation into the EMR is a difficult and controversial issue. Medical informatics researchers and hospital managers have for decades been pushing for the inclusion of more 'structured content' in the record (see, e.g., (McDonald, 1997)). Their aim is to eliminate or at least limit physicians' use of so-called 'free text' in the medical record and replace it with codes or 'structured data' which can be reused for secondary purposes such as clinical research, quality assessment, resource allocation, and billing (Rosenbloom et al., 2011). However, structured data entry has met with considerable resistance from clinicians who complain that it is too restrictive, time-consuming, and cumbersome (Powsner et al., 1998; Walsh, 2004; Khorana 2010; Lewis, 2011).

To make progress, we need to gain a better understanding of physicians' epistemic work and, in particular, of the principles and norms of clinical documentation practices, including the specific ways in which hospital physicians traditionally have documented the care and status of their patients in the medical record. The point of departure in this line of research is to recognize that the medical record as an institutional practice is immensely complex and variegated. This has been brought home, quite cogently, in fact, by a number of CSCW studies that have addressed the coordinative practices of clinical staff with special emphasis on the role of the medical record in these practices (e.g., Schneider and Wagner, 1992 [1993]; Hartswood et al., 2003; Bossen, 2006; Bansler and Kensing, 2010; Fitzpatrick and Ellingsen, 2013; Bossen and Jensen, 2014). A key finding emerging from these studies is that the medical record is better conceived of as a distributed system, an ecology of artifacts (Fitzpatrick, 2004; Bardram and Bossen, 2005; Schmidt et al., 2007). The medical record is a heterogeneous assembly of specialized representational and coordinative artifacts, typically spatially distributed and only occasionally and temporarily aligned spatially, and in any event only partially organized in a folder ('the working medical record', to borrow an apt phrase from Fitzpatrick, 2004). That is,

\footnotetext{
${ }^{4}$ The same conclusion is reached in a systematic literature review by Greenhalgh et al. (2009): 'while secondary work (audit, research, billing) may be made more efficient by the EPR, primary clinical work is often made less efficient' (p. 767).
} 
what has been established is that the medical record, as an 'ordering system', is adapted to support the high degree of specialization of clinical work.

However, in their analyses of the medical record, CSCW studies have generally overlooked the pivotal role of the physicians' clinical notes, such as admission notes and daily progress notes, and have not dealt specifically with their structure and content. As a result, $\mathrm{CSCW}$ research in this area has not yet taken fully into account the fact that clinical notes are a coordinative artifact of a rather special kind, a complex artifact consisting of a series of prose texts, written sequentially by doctors to facilitate and document their collaborative process of medical reasoning (as well as for administrative, legal, and research purposes). These notes document the patient's clinical course throughout his or her hospital stay by combining each physician's notes into an integrated file. They constitute, we argue, the core of the medical record and serve as a key means of communication and coordination among the physicians, nurses, and other health professionals who contribute to the patient's care.

\subsection{The study}

To begin addressing this gap in the literature, we present a detailed analysis of a set of physicians' clinical notes recording the acute hospitalization and subsequent treatment of a patient with chronic heart disease. Inspired by the concept of organizational communication genre (Orlikowski and Yates, 1994), we demonstrate that clinical notes are highly structured and conventionalized texts that promote conciseness and economy of expression while at the same time allowing physicians to express themselves in a precise and nuanced way. In further interpreting our findings we draw on a rich body of research on the discursive nature of clinical practice and the role of narrative in medical reasoning, emanating from the field of medical anthropology and the philosophy of medicine (e.g., Montgomery Hunter, 1991; Atkinson, 1995; Montgomery Hunter, 1996). This literature has provided a very important contribution to our understanding of the medical record in general and the clinical notes in particular - by grasping their function against the background of the nature of medical reasoning. We conclude that the success of future EMR systems will depend in great part on their ability to facilitate narrative reasoning, collaborative sensemaking, and distributed decision making.

The analysis we present in the following developed as a thread within a large fouryear research project conducted in collaboration with physicians and pacemaker technicians at the cardiology clinic of Rigshospitalet, Copenhagen University Hospital, which is a large tertiary hospital. The focal point of the project was the treatment of patients with chronic heart failure (i.e., reduced pumping function of the heart) and/or cardiac arrhythmias by means of Implantable Cardioverter Defibrillators (ICDs), an advanced type of pacemaker that uses electrical pulses or shocks to help control life-threatening arrhythmias (i.e., abnormal heart rhythms), especially those that can cause sudden cardiac arrest. Furthermore, it can store data about events that in turn can be downloaded wirelessly via a monitor in the patients home and transmitted to a secure server, which can be accessed by the hospital staff. The project 
involved, first of all, in-depth field studies to investigate existing documentation practices: observing the downloading of data from devices, tracing interpretation and migration of ICD data within the clinic, observing the use of medical records in consultations and interventions (Mønsted et al., 2011). Moreover, the project aimed at and involved the design and experimentation with prototypes for enhanced cooperation and information sharing among clinicians and between clinicians and patients (Bansler et al., 2010; Andersen et al., 2014; Mønsted, 2015).

It was evident from the outset that ICDs and similar implanted monitoring technologies already had had significant impact on the medical record as an institution, in that it had become further enlarged, subdivided, and fragmented, while the network of clinicians in need of being able to access the data, at some level of aggregation and interpretation, had expanded (Bansler et al., 2011). One of the key issues therefore became to understand the ways in which medical records, both at the cardiology clinic of Rigshospitalet and at a major regional hospital, were structured, maintained, aligned, and used. A selection of ten patient records (the central patient folders as well as 'satellite' archives, altogether about 5,000 pages) were examined and from that study, as well as from observations of consultations, the pivotal role of the clinical notes in the medical record became obvious (Bansler et al., 2013a). A subset of medical records concerning five patients was therefore selected and the clinical notes in these subjected to systematic scrutiny in order to understand their dual role as coordinative and representational artifacts. The present paper reports on the investigation of just one of these, namely, a series of clinical notes concerning one patient. It was chosen because it was the most rich or complex and therefore the most telling. In other words, the case is exemplary.

In order to bring out the role of the clinical notes in physicians coordinative practices and the way in which the format of the notes affords that role, we focus on how the physicians use narrative to make sense of the available evidence, construct plausible cause-and-effect relationships, and express degrees of certainty and uncertainty in very nuanced ways, and in doing so, we attempt to identify the structural, linguistic, and substantive conventions that guide the composition of clinical notes, that is, what JoAnne Yates and Wanda Orlikowski have termed 'genre rules' (1992).

The remainder of the article is structured as follows. Section 2 discusses the role of narrative in medicine and how it is incorporated into the traditional paper-based medical record. Section 3 introduces the setting, and section 4 presents the empirical case. In section 5 we analyze the data and present our findings, and in section 6 we summarize the results and discuss implications for the design of clinically useful EMR systems.

\section{The role of narrative in medical practice}

It is well documented that 'the practice of medicine is built upon and conducted through narratives: telling stories, listening to stories, editing, translating, and manipulating stories, and sharing stories' (Waymack, 2009, p. 218). 
When a patient presents with a complaint, the physician will listen to the patient's story, ask questions, possibly conduct a physical examination, and in doing so transform the patient's initial story into a medical narrative emphasizing possible diagnosis and action (Berg, 1992; Davenport, 2011); at morning conferences this tentative medical narrative ('the case') will be shared with other members of the medical team, discussed, elaborated, and perhaps compared with other similar cases (Atkinson, 1995); and at every handover - e.g., when a patient is transferred to another ward - the story is retold, albeit often in a highly condensed version. Further versions or excerpts of this story may be shared with nurses, laboratory technicians, radiologists and other clinicians who, in turn, may construct their own narratives which interpret and make sense of the data they produce (e.g., X-ray images) in light of the overall medical narrative (Rooksby and Kay, 2003). The point here is that images and laboratory data require an appropriate context to be meaningful:

[...] the lab data, so to speak, never speak for themselves. Those various data are delivered framed by some sort of narrative about this patient, however truncated, however impersonalized a form it might take. (Waymack, 2009, p. 220).

\subsection{Medical discourse and reasoning}

Students of medical practice like Drew Leder (1990), James Lock (1990), Fredrik Svenaeus (2000, 2003), and, in particular, Kathryn Montgomery Hunter (1992, 1996, 2006) have forcefully argued that medicine is an interpretive practice, in the sense that it focuses on understanding and treating the particular patient's condition and that it relies heavily on clinical judgment. Clinical judgment is characterized as a form of practical reason (Montgomery Hunter, 1996) and the construction and interpretation of narratives are considered central to it:

Like practical reason in fields such as jurisprudence and moral theology, clinical knowing is interpretive, a matter of making sense of what is going on at a particular place and time. The reasoner relies on skill in the interpretation of signs, practical familiarity with the customary way things work, and a thorough knowledge of the taxonomy of the possible in order to construct a retrospective account of what is going on for this patient at this time. Narrative is thus the principle medium of reasoning in medicine; it is not only the form taken by the expert's stock of clinical experience, it represents the process of clinical reasoning itself. (Montgomery Hunter, 2006, p. 310).

This does not imply that biomedical knowledge and clinical guidelines play no role in clinical practice. On the contrary, they are indispensable. The challenge the physician faces is to understand what is wrong with a particular patient in light of the 
general guidelines and the available epidemiological evidence. 'The clinical inquiry is an interpretive quest that circles between biology and epidemiology on the one hand and the circumstantial details of the patient's presentation of the symptoms and clinical signs of illness on the other' (Montgomery Hunter, 2006, p. 61).

This is a difficult task, not just because of the incompleteness of medical knowledge but also because illness manifests itself in different patients in different ways and because the available patient-related evidence in many cases is partial and ambiguous (Berg, 1992). The physician works 'backwards', from effect to cause, looking for patterns, searching for clues, making links between seemingly unconnected signs and symptoms, noting their progression, and testing possible diagnostic hypotheses (Montgomery Hunter, 2006). In these circumstances, the retrospective narrative reconstruction of events provides an appropriate means for physicians to make sense of the patient's condition:

Written or oral, [the case narrative] not only assembles the history of the patient's illness but also preserves the traces of judgments made, hypotheses eliminated and confirmed, actions taken and discontinued. The case both accommodates the multifactoriality of cause in individual instances of illness and works to normalize events as it records them for later use, including, when necessary, their reinterpretation. If a satisfactory solution is not forthcoming, the case narrative contains details that may prompt a new explanation or a new line of investigation. (Montgomery Hunter, 2006, p. 80).

This quote highlights that narrative is both a specific type of text and a mental construct. As a type of text, narrative is defined 'solely by its content' (Larsen, 2013): it is a representation in any medium (oral, written, still or moving pictures, etc.) of causally interconnected events occurring in time and space. As a mental construct or 'tool', narrative helps humans to organize their experiences and be able to communicate with others about them, and as such it is a powerful sensemaking device (Bruner, 1991). As Karl Weick has noted: 'Stories posit a history for an outcome. They gather strands of experience into a plot that produces that outcome' (1995, p. 128). Narratives are created retrospectively, they are reconstructions that search for a plausible causal chain of events capable of explaining what is going on, and their construction requires substantial editing and filtering of information (Weick, 1995).

Narratives are inescapably contingent and tentative, and therefore open to challenge and reinterpretation, created as they are by narrators 'whose standpoints are always situated, particular and uncertain' (Montgomery Hunter, 1996, p. 303). Instead of being a weakness, this contingent and provisional nature of narratives 'is also the source of narrative's strength and value' (ibid., p. 306) in the medical setting. Narratives allow physicians to express their thoughts in a nuanced and precise way, convey their degree of confidence in the available data, and articulate their uncertainties and concerns when proposing a diagnosis or a treatment plan (Hobbs, 2002). 
In sum, narrative is essential for knowing in medical practice. Physicians do not just use narrative to record information, but also, more importantly, as a tool for thinking and a means for communicating:

[Physicians] use narrative not only to store and recall information but as a pattern for observation, a template for thinking through new discoveries, and a primary medium for communicating and teaching both the regularities and the uncertainties of clinical practice. (Montgomery Hunter, 1996, p. 311).

So even with the introduction of more advanced EMR systems, more comprehensive coding schemes, and better interfaces to support structured data entry, narrative in medicine cannot be done away with and clinical information cannot be fully 'tamed and domesticated' (McDonald, 1997, p. 219).

\subsection{Narratives in the medical record}

The medical record serves many diverging purposes: as a working record it supports collaboration among physicians and other clinical staff (Berg and Bowker, 1997; Fitzpatrick, 2004), and as a permanent record it also serves as a legal document and as an important source of information for research, management, and quality assurance. Thus, it should be no surprise that the medical record has been subjected to various attempts at standardization and regulation since the early $20^{\text {th }}$ century as the modern hospital movement developed and public authorities became more involved with hospitals.

Before ca. 1900, institutional ${ }^{5}$ medical records were made retrospectively, some time after the discharge of the patient, and 'the techniques of recording cases were idiosyncratic and varied according to the style of the house' (Craig, 1990, p. 23). The main reason for creating these records was to advance medical education and research rather than to support patient care, and they 'were never intended to be working documents' (Siegler, 2010, p. 676).

After the turn of the century, government regulation as well as public and private accreditation schemes (such as the one provided by the American College of Surgeons) promoted the development of standards for record keeping at hospitals (Craig, 1989-90; Reiser, 1991b). At the same time, the medical record also gained a new role in clinical practice as it developed into an indispensable tool for clinicians to manage their patients and coordinate their work (Fitzpatrick, 2004).

As a result, the medical record underwent significant changes in structure and content. First, the record was transformed into a working document produced and

\footnotetext{
${ }^{5}$ Historical evidence suggests that, since the beginning of the modern age, individual physicians generally maintained some kind of records regarding their patients (e.g., McConaghey, 1960; Loudon, 1985; Reiser and Stanley 1991a, b; Pomata, 2010; Kassell, 2014; Pomata, 2014) but the evolution of these practices is beyond the scope of this article.
} 
used collaboratively by doctors, nurses, and others involved in the patient's care. Secondly, the traditional bound volumes of patient case files were replaced by loose files containing a mixture of different forms and types of documents:

Unlike the casebooks and journals, which contained summary observations and transcriptions of documents, the case files were constructed by arranging documents prepared by many people who participated in treating the patient, so that the case file was integrated into clinical practice. (Craig, 1989-90, p. 63).

The clinical notes (including admission notes and discharge letters) came to form the core of the record and in addition to these, a growing number of different types of reports (e.g., laboratory analyses and surgical reports), printed forms (e.g., temperature charts and diet cards), images (e.g., x-rays and photographs), and correspondence were collected together (Craig, 1989-90; Reiser, 1991b). The growth and diversification of the content of the record were related to the proliferation of new medical procedures and technologies:

Each novel procedure which was incorporated into hospital routines eventually achieved separate documentary status, and these additional documents swelled the average size of each file. (Craig, 1989-90, p. 77).

Standardization of the content of the record has been advanced by the development of standard nomenclatures and, in particular, by an increasing use of printed forms and rubber stamps with pre-defined categories (Craig, 1989-90; Siegler, 2010). In addition, over time, customary practices have developed that give clinical notes some structure and specific linguistic features:

[Physicians] have developed a number of conventions which serve both to standardize their written communications and to promote the economy of form that is crucial in a field where time pressure may be literally a matter of life or death. (Hobbs, 2003, p. 471).

The result is that today clinical notes constitute a well-established genre of clinical communication with a wide normative scope, which shapes how physicians organize, record, and share their observations and thoughts (Hobbs, 2003; Svenningsen, 2004). By 'genre', we here refer to a recognizable type of communication or, more precisely, to 'typified communicative actions characterized by similar substance and form and taken in response to recurrent situations' (Yates and Orlikowski, 1992, p. 299). The significance of a genre within a particular community is that it functions as an 'institutionalized template' (Yates and Orlikowski, 2002, p. 15) for communicative action, establishing a set of expectations that influence both how members interact and how communicative artifacts, such as the medical record, are interpreted and understood. 


\section{The patient folder at the cardiology clinic}

The cardiology clinic at Rigshospitalet treats patients from Eastern Denmark as well as Greenland and the Faeroe Islands. Patients with ICD implants have to be monitored on a regular basis, both in terms of ordinary cardiology and in terms of the functioning of the device. This is done by different clinical workers at different locations: on the one hand by the cardiologist at the patient's regional hospital and by the patient's own doctor (GP), and on the other by the ICD cardiologists, or 'electrical doctors' as they are called in the vernacular, at the cardiology clinic at Rigshospitalet and by the bio-technicians at the hospital's out-patient clinic who download and print data from the implanted device for specialist scrutiny. Newer ICD devices can be scanned remotely, while the patient is at home (via wireless download to a reader and subsequent transmission to the hospital over the Internet). The data then have to be recorded, filtered, interpreted, classified, put on record, handed over, etc.

The patient folder is the key artifact in the institutionalized coordinative practice that is the medical record. It has retained the appearance of the collection of notes, compiled as an aide memoire by a solitary doctor. But it is a coordinative artifact by means of which clinical actors keep each other up to date with respect to the state and treatment of a particular patient; with respect to each other's observations, plans, and occasional uncertainties; and with respect to the informational basis for clinical assessments and decisions.

The first thing to notice about a typical patient folder in the cardiology clinic is that it is thick (Figure 1). Enveloped by folded transparent vinyl it holds up to about 500 sheets of paper, some loose sheets, some stapled together. The cover can barely contain the content. The patient folder is hefty simply because it delineates the trajectory of chronically ill patients as represented in notes, lab reports, test results, clinical imagery, and so on that have accumulated over time, typically several years, and it thus gains size and weight over time.

Considered as a data structure, the patient folder is quite complex (Figure 2). Or rather, it is a motley of stuff, loosely collected in a folder. To provide some order, the

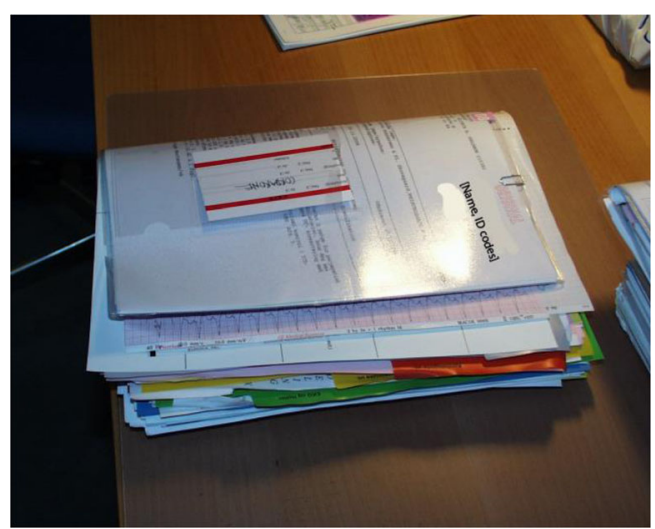

Figure 1. The patient folder of a patient with an ICD implant. 

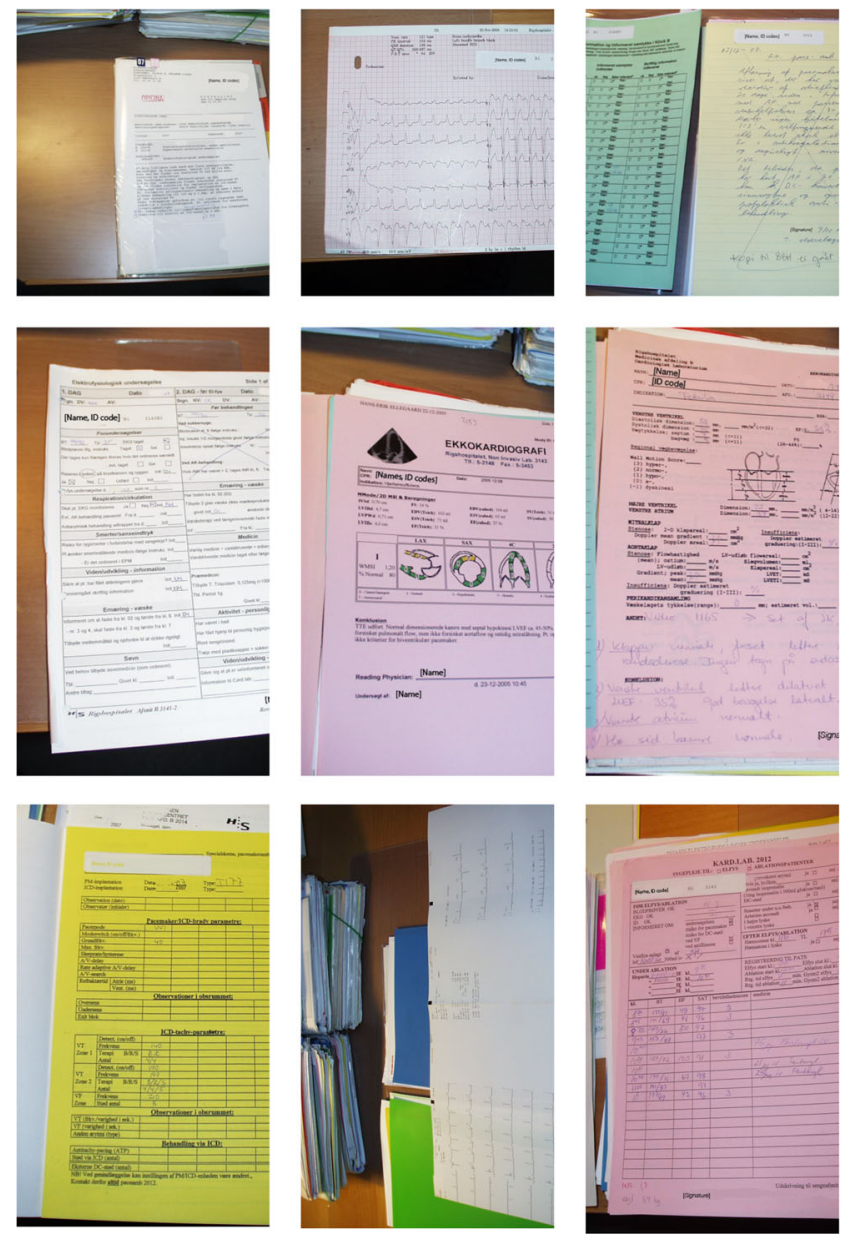

Figure 2. A sample of the multitude document and data types in the patient folder.

first sheet is a generic table of contents printed on a white sheet of plastic, and the content of the folder is organized into corresponding sections divided by colored separator sheets with inscribed tabs: 'Clinical notes' (grey), 'Cardiographic tests' (orange), 'Paraclinical tests' (yellow), 'ECG and Holter' (green), and 'Dispatch letters' (blue). Within each section, sheets are placed in inverse chronological order (with exceptions due to haste, mistakes, etc.).

An additional technique of organization is the use of colored paper to indicate the category of information carried by the sheets. Clinical notes are printed on ordinary white paper, administrative forms are printed on green paper, cardiographic test results are pink, references to other patients folders (in other clinics) are mauve, and so on. This coding scheme is not upheld consistently, however, as copies of test results etc., e.g., transmitted by fax or mail from other clinics, are on white paper.

The heterogeneity of document types is remarkable. Within the section labeled, say, 'Cardiological tests' one finds, in the case of one particular patient, 12 different 
document types, altogether about 50 documents. The other sections of the folder are similarly heterogeneous. As for data types, the heterogeneity is equally remarkable: text; numerical data series; tables; prose printouts, generated by means of word processor; handwritten prose; computer printouts with handwritten annotations and comments; forms generated by means of word processor, filled in by hand; computer-generated graphs; computer-generated X-ray imagery; etc.

Because of the number and sheer size of patient folders, the hospital's archive of patient folders is dispersed over multiple locations. Thus, when patients are due for checkup or have an appointment for a consultancy, their folders have to be retrieved. This task is carried out by the laboratory's clerical assistant who spends about three hours daily retrieving the folders for the patients scheduled for the same day, by locating them in one of the archives and hauling them back to the laboratory on a cart. Back at the laboratory, folders are placed on the desks or shelves of laboratory workers or doctors assigned to take care of the respective patients. In addition, folders are temporarily placed on shelves in case the patient did not turn up or is expected to come in for checkup within the next week. Finally, for a variety of reasons folders also find temporary station on doctors' desks in the various sections of the cardiology clinic, outside of the laboratory. Thus, because of the migration of patient folders, it may require considerable effort and time to locate and fetch a particular folder.

At the cardiology clinic, the medical record concerning a particular patient is not confined to the content of the patient folder. In fact, the clinical record is distributed over an assortment of paper-based and electronic archives and databases. In this context, the most important 'satellite record' is what is called the 'green folders' (Figure 3). It is a large set of suspension folders, housed in about 40 cabinet drawers in the hallway. Each folder contains information about a particular patient's ICD unit, its configuration, and printouts from the data accumulated by the unit. The 'green folders' are kept by the biotechnicians at the outpatient clinic and are only occasionally accessed by doctors. To counteract the fragmentation of the medical record and ensure a modicum of coordination across the two record systems, a summary of the 'read-out' (number of events, etc.) is manually entered into the clinical notes in the patient folder (Figure 4).

The time-honored patient-centered medical record has worked well for centuries and has proved very flexible in its contemporary incarnation as an
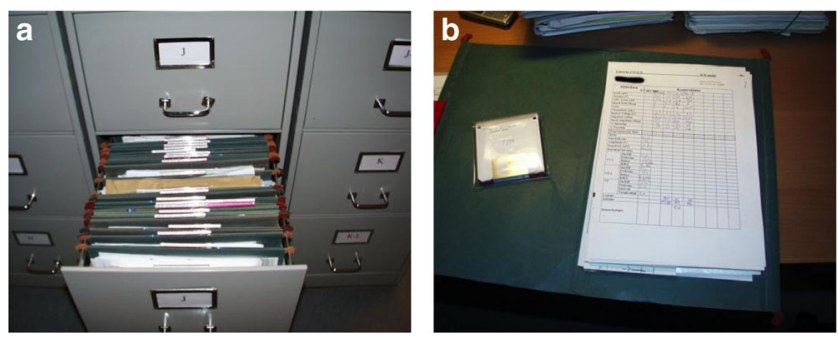

Figure 3. The 'green folders': (a) Suspension file system of pacemaker and ICD data, organized by patients' personal ID codes. (b) Test data: schema filled-in by hand. 


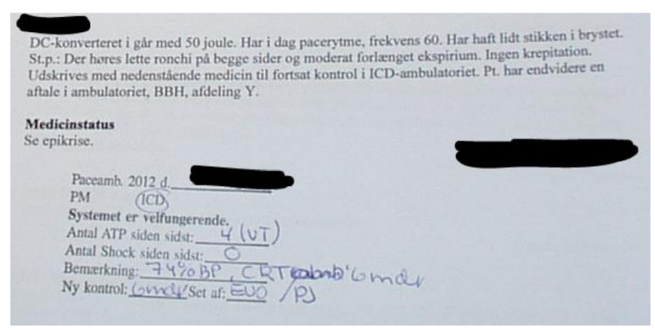

Figure 4. A summary of the 'read-out'of an ICD (number of events, etc.) is manually transferred to the clinical notes in the patient folder, using a stamp with empty fields.

institutional coordinative artifact. However, it now shows all the signs of coming apart. The sheer size and heterogeneity of patient folders for patients with chronic illnesses make it difficult for a busy clinician, in the context of a brief routine consultation, to obtain an overview of the patient's history. In addition, its robustness as a dynamic shared representation of the state of the patient was predicated on its being localized: a center of documentation and coordination of a local and specialized clinical cooperative work practice; but this condition is undermined by, inter alia, the emergence of satellite records, in this case the archive of ICD data managed by bio-technicians. This puts additional load on the clinical notes as a means of coordinating and integrating clinical work.

\section{Clinical notes: an example}

We shall here follow the acute hospitalization of an elderly man, Mads Jensen. ${ }^{6} \mathrm{He}$ has a long history of heart disease and has been hospitalized several times at different hospitals in the past for heart failure. He has been diagnosed with paroxystic atrial fibrillation, the most common cardiac arrhythmia. It is a fast irregular heart rhythm that occurs occasionally. To control his arrhythmia, Mads Jensen takes several kinds of medicine. In this case, the hospitalization lasted 29 days and involved a series of complications, some of which were life threatening. He was first admitted to a local general hospital (referred to below as the 'General Hospital') for five days and later transferred to Rigshospitalet.

During this period, the physicians produced 28 pages of typewritten text. ${ }^{7}$ A copy of the clinical notes produced at the General Hospital was passed on to the physicians at Rigshospitalet when the patient was transferred.

\footnotetext{
${ }^{6}$ We have obtained written consent from the patient to publish excerpts from his/her medical records. All names, dates, and other identifying information have been changed.

${ }^{7}$ At the time of the study, progress notes at the hospitals in question were dictated digitally by the physician, typically immediately after examining the patient, for instance upon admission or during a ward round, and later typed by a medical secretary, printed out, and added to the patient's medical record (today they are also available in electronic form). The notes are usually recorded daily, but for patients in critical care, notes are typically made several times a day.
} 
Physicians in Denmark have, by law, an obligation to keep accurate medical records for each patient that reflect the care and treatment provided. The records must provide a comprehensive medical history, containing details of examinations, diagnosis, and treatment. The types of information that must (if relevant) be included in the patient's medical record are defined in a ministerial order. ${ }^{8}$ The list of prescribed information is quite long, but there are no requirements regarding the format of the records (besides the demand that they are in Danish). The records may be electronic or paper based.

Nonetheless, the clinical notes from the two hospitals, which we analyze here, are very similar not just in structure and content, but also in layout and style. ${ }^{9}$ They are representative examples of clinical notes produced within the fields of cardiology and intensive care in Denmark. Of course, every patient is a unique case, but the two sets of clinical notes presented here are typical in terms of their content, language, formatting, and structure.

\subsection{Acute hospitalization}

Mads Jensen is admitted to the cardiology department at the General Hospital by ambulance on 27 May, in the evening, with the diagnosis of atrial fibrillation with fast heart rate and promptly treated with an intravenous injection of Amiodarone (Cordarone ${ }^{10}$ - an antiarrhythmic agent used for various types of tachy-arrhythmias (fast cardiac arrhythmias). This has an immediate positive effect and slows the heart rate (the ventricular rate) to about 80 beats per minute. However, he very soon develops sweating and seizures and has cardiac arrest. Resuscitation is initiated according to the hospital's guidelines for advanced life support (ALS) ${ }^{11}$ and after 6 minutes treatment he has restoration of spontaneous circulation. He is still unconscious and the physicians decide to transfer him to the Intensive Care Unit

\footnotetext{
${ }^{8}$ Bekendtgørelse no. 1373, 12 December 2006.

${ }^{9}$ Medical secretaries in Denmark are taught how to format and type clinical notes during their education. They learn about date and time formats, tabulator settings, line spacing, common abbreviations, when to use Roman or Arabic numerals, when to capitalize letters and words, how to spell Latin words, etc. The schools have agreed upon a common standard for the layout and typing of clinical notes, see $\mathrm{http}: / \mathrm{www} . \mathrm{e}-\mathrm{pages} . \mathrm{dk} / \mathrm{hk} / 738 /$ fullpdf/full4e3a6a0571444.pdf.

${ }^{10}$ Amiodarone is the active ingredient in Cordarone (and other brand name drugs). In this context it is to be taken as a synonym of Cordarone.

${ }^{11}$ Advanced Life Support (ALS) is an emergency procedure performed to manually support breathing and circulation with the aim of preserving intact brain function until the patient has a return of spontaneous circulation (ROSC) or is declared dead.
} 
(ICU) for therapeutic cooling to reduce the risk of brain injury. The admission note reports: ${ }^{12}$

\subsubsection{1:15 CWARD \\ Admission}

64-year-old male admitted w.d. atrial fibrillation with rapid heart rate.

\section{Previous}

Known with paroxystic atrial fibrillation, treated with ablation in fall 2006 .

30.01.07 CAG done at GH without indication for revascularization. Ventriculography with normal LVEF.

Has reportedly mainly been treated at LOH, according to his son he has been hospitalized at LOH for most of 2006 .

Furthermore had PCI.

\section{Present}

Is admitted with fast atrial fibrillation, comes in with wide complex tachycardia, as mentioned known with left bundle branch block, in acutely bad shape, respiratory and circulatory. Is awake and has communicated with the staff. Complains of nausea and would like a bag to throw up in. Due to fast, broad complex tachycardia there is given

rp. inj. Cordarone $300 \mathrm{mg}$ as bolus IV

with good effect on the ventricular frequency, which falls to about 80 . Still wide QRS complexes. Pt becomes pale and cold sweating, gets seizure like twitches in the face and the extremities. Pt becomes unconscious and his respiration fails, cardiac arrest is diagnosed and basic resuscitation 30/2 is commenced. Telemetri shows bradycardia down to 30 . There is given

and after $4 \mathrm{~min}$

rp. inj. Atropine $3 \mathrm{mg}$ IV inj. Adrenalin $1 \mathrm{mg}$ IV

Pt has an acceptable systolic BP between 110-140. Does not wake up at all and is intubated. He still has seizures with grimacing movements in the head-neck region, pt conferred with doctor HM, pt is transferred to ICU for cooling.

12 The excerpts from the progress notes have been translated from Danish by the authors. 
There is an ABG with pH 6.9, PCO2 9.2, PO2 10, BE-16.9, N 138, K

3.8, glucose 15.6, lactate 9.5.

Provisional biochemistry: Leuc. 17.8, thromb. 220, Hb 8.3.

Christian Nielsen/gl

This note recounts a quite dramatic episode, but is otherwise unremarkable in that it follows a fairly standard structure and is written in the usual format and style of clinical notes in this hospital. It illustrates several important features of clinical notes. First, we notice the standardized layout with headers and indentations that allow the reader to quickly locate information of interest. Second, the note is clearly identified by the acronym of the ward ('CWARD,' the cardiology department), the name of the dictating physician ('Christian Nielsen'), the initials of the medical secretary who typed it (' $\mathrm{gl}$ '), and date and time. Third, the note is written in a technical language using medical terms and standard abbreviations ${ }^{13}$ such as 'Pt' (Patient) and 'PCI' (Percutaneous Coronary Intervention, i.e., a balloon angioplasty of a coronary artery stenosis). Furthermore, initials and local abbreviations are often used instead of the full names of people and organizational units (e.g., 'GH' for General Hospital). Fourth, the note is written in a concise format and it relies heavily on the reader's background knowledge, both of medicine and of local circumstances such as the organization of the region's hospital system. For instance, no reason is given for the decision to cool down the patient, because this is a standard procedure for patients with cardiac arrest.

The structure of the note follows a common pattern: chief complaint, typically one sentence that introduces the patient and the principal reason for the admission; the medical history prior to the current admission (under the heading 'Previous'); a short account of the current admission (under the heading 'Present'); the physical examination of the patient, which in this case is quite rudimentary and leads directly to the initiation of treatment; and finally a rather truncated assessment and plan, which simply states that the patient should be cooled down. The note ends by listing a number of laboratory findings (which is quite common in acute cases, such as cardiac arrest).

It is characteristic that the account given in the note locates the current episode in the temporal framework of the overall illness trajectory of the patient and constructs a chronology that identifies significant events and arranges them in a logical order. The turning point in the narrative is the sudden onset of sweating and seizures leading to cardiac arrest, which is described quite graphically. No explanation for the cardiac arrest is given, but the narrative hints at the possibility that it is caused by the injection of Cordarone (Amiodarone).

${ }^{13}$ A list of abbreviations used in the excerpts from the progress notes can be found in Appendix A. 


\subsection{Transfer to the Intensive Care Unit (ICU)}

Mads Jensen is then transferred to the ICU at the hospital where therapeutic hypothermia (cooling) treatment is initiated. After the transfer, a new admission note is added to his medical record, this time composed by an intensive care physician. This admission note has many similarities with the previous one. The layout and style of writing is the same and it follows the same overall structure, beginning with the chief complaint and ending with the assessment and plan. However, it is more detailed and a number of new subheadings have been added: e.g., 'Allergies', 'Medications', 'Alcohol', 'Tobacco', 'Assessment' and 'Plan' (see Appendix B, where the complete note is reproduced).

Furthermore, under the subheading 'Present', the note includes a systematic review of organ systems: 'CNS' (Central Nervous System), 'Resp.' (Respiratory), 'CVS' (Cardiovascular System), 'Abd.' (Abdomen), 'Ren.' (Renal System) and 'Hem.' (Hematology):

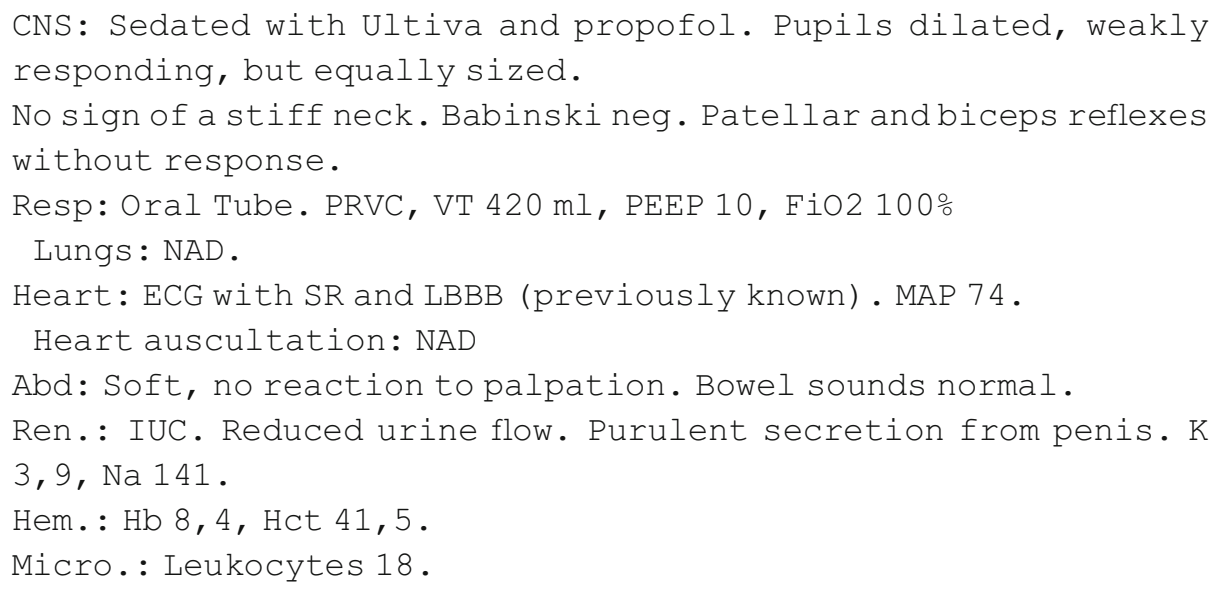

The plan is organized according to the same principle, namely by addressing each organ system in turn. This is a typical way of organizing the clinical notes in intensive care units, sometimes referred to as the 'organ system approach' (Irwin et al., 2008, p. 1843). This format ensures that each physiologic system is addressed in a comprehensive and methodical way:

\begin{tabular}{|c|c|c|}
\hline \multicolumn{3}{|l|}{ Plan } \\
\hline \multirow[t]{2}{*}{ Re CNS : } & rp. & sedation \\
\hline & rp. & cooling for $12-24$ hours \\
\hline \multirow{6}{*}{$\begin{array}{l}\text { Re Resp: } \\
\text { Aim at } \\
\text { Re CVS: } \\
\text { and }\end{array}$} & $r p$. & x-ray thorax \\
\hline & & $\mathrm{PO} 2>9, \mathrm{PCO} 2<7$ \\
\hline & rp. & coronary enzymes \\
\hline & & ECG at times $0,6,12,18,24$ hours \\
\hline & rp. & D-dimer \\
\hline & rp. & MAP $>65$ \\
\hline
\end{tabular}




\begin{tabular}{|c|c|c|}
\hline \multirow{3}{*}{ Re Abd: } & & \multirow{3}{*}{$\begin{array}{l}\text { pause Isoptin } \mathrm{R} \\
\text { parenteral nutrition } \\
\text { insulininj. cf. instructions }\end{array}$} \\
\hline & rp. & \\
\hline & rp. & \\
\hline & rp. & \\
\hline Re Ren: Aim at & rp. & $\begin{array}{l}\text { Urine production per hour }>1 \\
\mathrm{ml} / \mathrm{h} \text { by volume therapy }\end{array}$ \\
\hline Aim at & & K 4.0 \\
\hline Re Microbiol.: & rp. & cultivation incl. urethra \\
\hline & rp. & cefuroxim \\
\hline In addition & rp. & $\begin{array}{l}\text { Mg and } P \text { at times } 0,12,24, \\
36 \text { and } 48 \text { hours }\end{array}$ \\
\hline & rp. & I-status, liver + coag. counts \\
\hline
\end{tabular}

No reasons are given for the individual elements in the plan. It is assumed that the reader is familiar with intensive care procedures and can figure out for him- or herself why the specified actions should be taken. For instance, cardiac (or coronary) enzymes are biochemical markers for acute myocardial infarction (commonly known as heart attack) and should therefore be checked ('rp. coronary enzymes'). Another example is that MAP (Mean Arterial Pressure) should be kept above $65 \mathrm{~mm} \mathrm{Hg}$ ('rp. MAP >65'), because the inner organs otherwise do not receive enough oxygen. When suboptimal, MAP can be increased by using, for instance, norepinephrine (or noradrenaline), which in fact happens later in the process, according to the clinical notes.

Perhaps more interestingly, this admission note once again recounts the story of how Mads Jensen was admitted to the hospital with atrial fibrillation, how he developed cardiac arrest after treatment with Amiodarone IV, and how he was resuscitated and transferred to the ICU. But this time the story is retold with more emphasis on the patient's neurological state and the risk of brain damage due to insufficient oxygen supply during the cardiac arrest and less emphasis on the patient's cardiological problems:

\section{Present}

Pt admitted tonight by ambulance due to AF with 1:1 conduction. General condition affected by this. In addition dilated unresponsive pupils observed. In the admission room at C 23, Cordarone is given and pt becomes momentarily unresponsive, has generalized tonic-clonic seizures and goes into clinical cardiac arrest. In the beginning what looks like VT, but before we get to give a shock, then asystole. Chest compressions and ventilation is started and atropine $3 \mathrm{mg}$ and adrenalin $1+1 \mathrm{mg}$ are administered. Pt is intubated. After 6 min. of ALS pt has spontaneous circulation again. GCS 3. Gets intermittent jerks, is grimacing on the tube and increases to GCS 6 . First ABG with $\mathrm{pH}$ 6.92, $\mathrm{PCO} 2$ 9.21, $\mathrm{PO} 2$ 10.1, BE 16.9, lact. 9.5. 
Infusion with bicarbonate $100 \mathrm{ml}$. is administered. Transferred to ICU, where cooling, sedation is commenced. Bladder catheter and an arterial line are inserted and a 5-lumen CVC is placed in the rightsided external jugular vein (right side due to marevan). ${ }^{14}$

First, it is noted that the patient had 'dilated unresponsive pupils' when admitted to the hospital, which can be a sign of brain injury. Second, it is recorded that 'GCS [is] 3' immediately after the successful resuscitation and that it later increases to 6. GCS is an acronym for the Glasgow Coma Scale, a neurological scale that aims to give a reliable, objective way of assessing the state of consciousness of a person. ${ }^{15}$ Third, many of the specific cardiological data, such as information about ECG readings, blood pressure, and heart rate are omitted from this version of the story, and the evocative account of how the patient starts sweating and develops severe muscle seizures is replaced by the matter-of-fact statement that the patient develops 'generalized tonic-clonic seizures'.

During the night, the ICU staff succeeds in stabilizing the patient, and he is kept sedated and cooled down to $32{ }^{\circ} \mathrm{C}$. At midnight, after 24 hours of hypothermia treatment, they begin slowly warming him up again and the next morning (29 May) he is awake and able to communicate by nodding his head as sign of yes or no, although still partially sedated. However, the ICU physicians now have a new worry: the patient's white blood cell count is rising (sign of infection) and he has developed a pleural effusion (accumulation of water in the chest cavity) that could be caused by pneumonia. They decide to immediately start antibiotic treatment.

The cause of his heart arrest is also still unresolved. They send for a cardiologist to perform an echocardiography (a cardiac ultrasound) to assess the patient's cardiac condition. The cardiologist arrives at noon and after examining the patient, he dictates a comprehensive clinical note.

The note starts, once again, by reviewing the patient's history - but this time the primary focus is on his heart troubles, which are discussed in much more detail than before. The note confirms some information, for instance that Mads Jensen, according to his family, took Cordarone tablets for his atrial fibrillation, but it also questions previous information about his having a coronary angioplasty at some point (referred to as a PCI, percutaneous coronary intervention, in the clinical notes):

Previously thoroughly examined for ischemic heart disease by coronary arteriography, first at RH, Feb. 05, reportedly without remarks, thus no need for PCI. New coronary arteriography at our department 30.01 .06 was still without significant stenoses.

\footnotetext{
${ }^{14}$ An oral anticoagulant. Marevan is the Danish brand name for this drug (Warfarin).

${ }^{15}$ The scale provides a score in the range 3-15, in which progressively higher scores indicate higher levels of consciousness. Patients with scores of 3-8 are usually said to be in a coma.
} 
Furthermore, the note adds two new pieces of information about his heart problems. It describes how he has been free of symptoms until 4 months ago, but then began having episodes of difficulty breathing and palpitations, and it discusses in detail an ECG printout from the ambulance, which has not been mentioned before:

Print out from the ambulance shows, on the first beats, what looks like the well-known SR with left-sided bundle branch block and then sudden change to a regular wide complex tachycardia, rate 187 BPM. This could very well be a case of $2: 1$ conducted atrial flutter.

After the review of the patient's recent medical history follows a discussion of the most likely reason for the cardiac arrest. First, it is pointed out that cardiac telemetry (i.e., long term in-hospital monitoring of the heart rhythm) conducted after the cardiac arrest shows 'severe prolongation of the QT interval, ${ }^{16}$ up to $600 \mathrm{~ms}$, which confirms the suspicion of an acute Amiodarone effect'. Second, it is noted that a test carried out the same morning shows that the level of troponin $\mathrm{T}$ (a cardiac protein which is leaked into blood during cardiac injury) is normal, 'which weighs against the suspicion of acute ischemic genesis and consequently against the suspicion of ventricular arrhythmia'. However, no firm conclusion is reached:

On ward C23 perceived as circulatory instable, which is why IV Amiodarone was administered. At first, it apparently stopped the SVT, but also caused SA block leading to severe bradycardia and clinical cardiac arrest.

Subsequent telemetry shows severe prolongation of the QT interval, up to $600 \mathrm{~ms}$, which confirms the suspicion of an acute Amiodarone effect.

Biochemical measures this morning show normal troponin $\mathrm{T}$, which weighs against the suspicion of acute ischemic genesis and consequently against the suspicion of ventricular arrhythmia. [ 29.05.2009 at 12:00]

The note ends with a cardiological assessment and plan. The 'most probable' diagnosis is recorded as 'paroxystic atrial fibrillation and atrial flutter that despite Cordarone are being conducted with a high rate to the ventricles'. Consequently, the cardiologist recommends that the patient resumes taking his usual Amiodarone (Cordarone) tablets as soon as possible. At the same time, he warns against giving more IV bolus injections (the injection of a drug in a high quantity, called a bolus) of Amiodarone.

${ }^{16}$ The QT interval is measured on an electrocardiogram (ECG). 


\subsection{Life threatening crisis}

Mads Jensen's condition seems to be improving and the expectation is that he can be discharged from the ICU and transferred back to the cardiology ward within a day or two. However, after the morning round the next day (30 May), the physician is very concerned about his infection. She notes that 'Pt has rapidly increasing biochemical markers of infection, possibly stemming from pneumonia', despite treatment with antibiotics. She decides to call for a microbiological specialist, who thinks it is too early to tell whether the antibiotics are effective or not and advises to 'wait and see'.

The next morning (1 June), Mads Jensen has difficulties breathing and his condition deteriorates rapidly. The physician's apprehension shows clearly in the note he makes after the morning round:

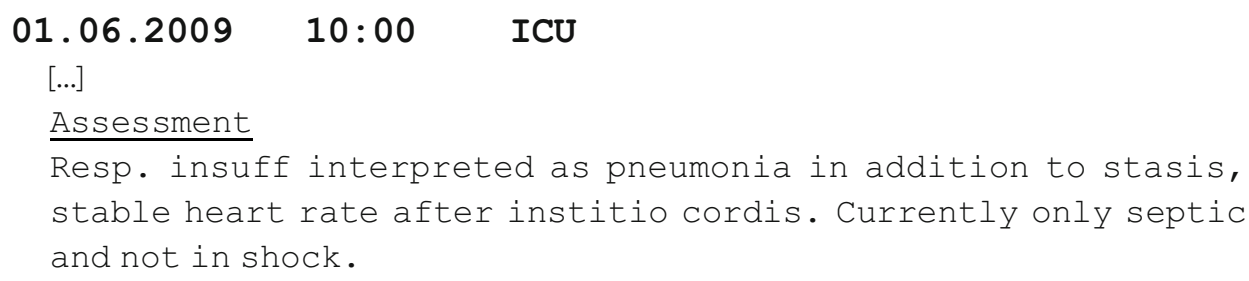

He has a strong suspicion that the patient in fact has pneumonia and that it is getting out of control. The short fragment 'Currently only septic and not in shock' is full of foreboding. It means that the patient now has developed sepsis (a severe, potentially fatal complication to bacterial infections where the infection triggers a variety of delirious disease processes causing manifestations such as bleeding, coagulation, and shock), which may lead to septic shock (a medical emergency that occurs when an overwhelming infection leads to life-threatening low blood pressure).

Four hours later, the same physician notes that Mads Jensen has developed atrial fibrillation and speculates whether the underlying cause is heart failure or sepsis:

\section{$01.06 .2009 \quad 14: 00 \quad$ ICU}

Increasingly circulatory unstable, AF 130-150. Could be caused by worsening heart failure, but it could also be due to worsening septic condition.

He decides to call for a cardiologist. The cardiologist tries three times to restore a normal heart rhythm with DC cardioversion, ${ }^{17}$ but without success, and then recommends trying to regulate the atrial fibrillation (i.e., decrease the pulse rate) by giving

\footnotetext{
${ }^{17} \mathrm{DC}$ (Direct Current) cardioversion is a medical procedure by which a cardiac arrhythmia is converted to a normal rhythm, using electricity. It is performed by giving the heart an electric shock, at a specific moment in the cardiac cycle. In contrast, pharmacologic cardioversion, uses antiarrhythmic medication instead of an electrical shock.
} 
three IV injections of Digoxin at 6 hour intervals (referred to as 'digitalization') despite the bad experience with the Amiodarone bolus four days earlier, which possibly led to his cardiac arrest.

The 'digitalization' is without effect and the next morning (2 June), after consultations with a cardiologist, the ICU physician decides to transfer Mads Jensen to Rigshospitalet, which as a large tertiary hospital is better equipped to treat heart failure and sepsis.

\subsection{Transfer to the heart center at Rigshospitalet}

Mads Jensen is transferred to the ICU at Rigshospitalet and after three days they succeed in controlling the sepsis and restoring a normal heart rhythm. However, he still has episodes of supraventricular tachycardia (SVT) and the cause of his heart arrest is still unclear. Was it caused by ventricular tachycardia or by the Cordarone injection? The physician notes that this is difficult to tell from the clinical notes they have received from the general hospital when Mads Jensen was transferred to the heart center:

\subsection{6 .09}

Plan

Satisfactory condition, is about to be without need of intensive care, has a history of undetermined cause of cardiac arrest, difficult to infer from the clinical notes whether the cause really was ventricular tachycardia/ventricular fibrillation. Is primarily described as bradycardia after Cordarone inj.

After many more tests and several conferences among the electrophysiological specialists at the heart center, and after considering a pacemaker or ICD, ${ }^{18}$ the cardiologists opt to treat his arrhythmia with ablation therapy. ${ }^{19}$ This seems to be successful, and on 26 June, a month after his initial hospital admission, Mads Jensen is discharged again - as the physician records in his chart: 'Therefore - finally ready for discharge.'

Mads Jensen is discharged, but his case remains unresolved in the sense that the underlying cause of his sudden cardiac arrest and, more broadly, his recurrent episodes of arrhythmia, is still unknown when he leaves the hospital. The collective story told by the many different physicians involved in his case and documented in the clinical notes from the two hospitals is left unfinished and the mystery of his sudden cardiac arrest remains unsolved.

\footnotetext{
${ }^{18}$ An implantable cardioverter-defibrillator (ICD) is a device that detects any dangerously abnormal heart rhythms. The device is connected to leads positioned inside the heart. These leads are used to monitor the cardiac rhythm, deliver electrical shocks in case of life threatening tachycardia, and sometimes pace the heart, as needed. The various leads are connected to the ICD, which is implanted in a pouch created under the subcutaneous layer of the skin of the chest wall.

${ }^{19}$ Cardiac ablation is a procedure that is used to destroy small areas in the heart that may be causing heart rhythm problems. During the procedure, a catheter is introduced from a peripheral vessel and placed inside the heart to measure the heart's electrical activity and to destroy the areas of the heart responsible for initiating arrhythmias.
} 


\section{Characteristics and functions of clinical notes}

As the case shows, the medical record should be conceived of as far more than a set of records, or an 'ecology' of artifacts, but rather as a quite special ordering system in which the clinical notes perform an essentially epistemic function and in that capacity serve as the integrative force at the center of the cloud of orbiting inscriptions and artifacts.

Physicians' clinical notes are produced in an open-ended, enormously variegated, and essentially contingent, epistemic process (Strauss et al., 1985; Atkinson, 1995; Montgomery Hunter, 2006). The notes concerning a particular patient constitute a working document that 'records the core narrative of the patient's medical care' as it unfolds over time (Hobbs, 2003, p. 454). They are usually recorded daily, but for patients in critical care, notes may be made several times a day. They do not just describe the patient's condition and the treatment given, but also the physician's thinking about what is going on and what is planned. In this way, they serve both as a tool for thinking for the individual physician, enabling him or her to make sense of the patient's past history and current condition, and as a coordinative artifact used by physicians, nurses, and other health care professionals.

\subsection{Genre characteristics}

The epistemic function of clinical notes is clearly reflected in the way they are composed and formatted. The conventions guiding their form and substance have developed over more than a century and play a cardinal role in medical practice today. It is therefore useful to conceive of the format of clinical notes as a particular 'genre' of clinical communication (next to discharge letters, lab reports, etc.). In the words of Yates and Orlikowski, a 'genre' functions in a given community as an 'institutionalized template' for communicative action, by establishing a set of takenfor-granted expectations that influence both how communicative artifacts are routinely composed, interpreted, and understood (Yates and Orlikowski, 2002, p. 15).

In the following, we will briefly summarize the genre characteristics of the clinical notes from the two hospitals. First of all, it is worth noting that they belong in the first section of the patient folder (see Section 3), which is indicative of their importance. They are placed in the file in chronological order, with the most recent notes on top. The notes are authored by the physicians who are directly responsible for the treatment of the patient. (The clinical notes are the preserve of the physicians. Nurses maintain their own clinical notes, which are placed at the back of the patient folder). Physicians dictate their notes digitally, typically immediately after examining the patient, for instance upon admission, or during a ward round. Later, the notes are transcribed by a medical secretary, printed out, and added to the patient's medical record.

The primary intended readers of the physicians' clinical notes are the - usually quite small - group of physicians currently involved in the patient's care. Secondary readers include nurses, physiotherapists, and various other health professionals who care for the patient. Tertiary readers include administrative personnel as well as future 
care takers. For instance, if the patient is transferred - or later admitted - to another hospital, it is normal practice to send a copy of the clinical notes to this hospital.

From the case we can distill a set of important genre-specific features of the clinical notes:

(1) The predominant principle of organization is chronological. Not only are the notes placed in chronological order in the patient folder, temporal order is also the main ordering principle for each individual note (more about other ordering principles in Section 5.3). The notes identify important states (e.g., 'atrial fibrillation') and significant events (e.g., 'DC cardioversion') and arranges these in relative temporal order (narrative time). The implication is that there is a (possible) causal relationship between the events and the states that are being narrated (e.g., DC cardioversion may stop the atrial fibrillation and put the heart back into normal sinus rhythm).

(2) The notes contain numerous references to other documents and data sources such as lab results (e.g., blood work including blood cell count, electrolyte levels, and coagulation profile), ECG print-outs, telemetry print-outs, X-rays, CT scans, echocardiograms, and fluid balance charts. In this way, the clinical notes weave together information from a variety of sources and function as an 'index' for the multitude of different documents in the patient record, which can guide the reading process.

(3) The notes have a standardized layout and are clearly identified by date and time, author, and transcriber. As a guide for readers, the main body of the note is divided into sections with relatively standardized headings - e.g., 'admission,' 'previous,' 'present,' and 'plan' - and indentations are used to accentuate prescriptions and orders and make it easy to spot them in text.

(4) The format is concise. The notes are written in medical language using highly specialized terminology as well as shorthand, acronyms, and abbreviations some of which are standardized and common while others are more local and idiosyncratic. Therefore, understanding the text requires a great deal of background knowledge concerning not only medical terminology and procedures, but also local circumstances and resources. As pointed out by Hobbs, a clinical note is a 'condensed text' in which 'the reader's background knowledge supplies the cohesion that is provided by explicit linkage in other contexts' (Hobbs, 2003, p. 459).

(5) Substance, organization, and style varies from one medical specialism to another. Each group of specialists addresses 'concerns that reflect the unique philosophy and skills of that professional group' (Poirier and Brauner, 1990, p. 30). The cardiologists, for instance, focus on cardiovascular disease and hone in on such issues as blood pressure, heart rate, and echocardiography, while the ICU physicians usually have a broader perspective, taking a more systemic approach to treatment. In other words, the stack of clinical notes reflects the complexity of medical work in the hospital setting and, consequently, they lack 'the ultimate cohesiveness of a single author or point of view' (Poirier and 
Brauner, 1990, p. 37). For instance, in the previous section, we saw how different specialists - while adhering to the conventions of the clinical note genre - construct noticeably different clinical narratives, each foregrounding certain events and types of data. The cardiologist's note from 29 May, for example, pays particular attention to the patient's history of heart arrhythmia, what kind of anti-arrhythmia medications he was taking before being hospitalized, the electrocardiogram (ECG) taken in the ambulance while on his way to the hospital, his troponin $\mathrm{T}$ level (a cardiac enzyme), etc.

\subsection{Types of notes}

We have hitherto described the general characteristics of the clinical notes genre. However, as Mads Jensen's case shows, physicians employ several different kinds of notes dependent on the situation and the requirements for record-keeping. In Mads Jensen's case, we can identify five main types of notes: (1) admission notes, (2) daily progress notes, (3) consult notes, (4) conference notes, and (5) event-based or ad-hoc notes.

Admission notes (often referred to as 'summaries' by the clinicians) are taken as the patient move across transition points of care, for instance when a patient is first admitted to the hospital or transferred from one ward to another. As noted by Poirier and Brauner (1990), these transition points are of particular importance, because 'the patient is seen through new eyes' and, consequently, 'prior history and hospital course are usually reviewed and assessments reformulated' (p. 35). It is therefore not surprising that these notes are among the most comprehensive and codified.

Admission notes are typically organized into the following main sections: (a) chief complaint, i.e., the reason for hospitalization or for transfer from another ward or hospital, (b) allergies, (c) medications on admission, (d) tobacco and alcohol use, (e) past medical history, (f) history of present illness, (g) laboratory data, images, and results from the physical examination of the patient, (h) assessment, and (i) plan and orders. Although the exact order of the sections may vary, some sections may be merged into one, and some sections may be omitted while others are added (e.g., exposures to antibiotic-resistant hospital bacteria), the overall composition generally follows this pattern. ${ }^{20}$

It is characteristic that the admission notes place the current episode in the context of the patient's overall illness trajectory and provide a brief 'summary' of the patient's history, clinical picture, test results, etc., which is considered highly useful by clinicians. Admission notes are, therefore, frequently read to get a quick overview of the patient's situation, for instance in preparation for a consultation (Mønsted, 2015).

Daily progress notes are recorded after the ward round in the morning. They have the same basic structure as admission notes except they usually omit the 'background' sections (a) to (e), and vary much more in terms of scope and detail - from

${ }^{20}$ An example of a complete admission note is reproduced in Appendix B. 
very thorough and detailed (a couple of pages) to relatively brief or even quite rudimentary notes (a few lines), depending on the condition of the patient. The daily progress notes represents 'slices of time'. Montgomery Hunter (1991) likens them to a 'laboratory's bench notebook [...], which tracks progress of a scientific experiment - or several interactive experiments at once - day by day, interval by interval' (p. 85).

Consult notes are dictated by medical specialists summoned to assess the patient. Mads Jensen, for instance, was seen by cardiologists (three times), an endocrinologist, and a hepatologist during his hospitalization. The consult note typically starts by stating the reason for the consultation (e.g., 'consultation requested because of recently developed liver problems'[15.06.2009]). Subsequently, it roughly follows the same structure as the admission notes, the main difference being that sections deemed irrelevant to the task at hand are omitted. Another difference is that the assessment section typically is very methodical and meticulous. The total length of the consult notes varies from a half to one and a half pages.

Conference notes summarize the recommendations from morning or lunch conferences. They are quite brief, and beyond listing the participants, they simply state the conclusion and its premises in a couple of sentences.

Event-based notes are dictated at irregular intervals, whenever a physician is called to see a patient for a significant event or change of condition. These notes vary very much in both length, style and composition. Some of them resemble short versions of the daily progress notes, but others do simply document an intervention (e.g., DC cardioversion), give an order, or raise a question.

The various types of notes work in a way that is similar to a research group's evolving repertoire of papers and laboratory notes: some entries serve to lay the groundwork by defining the key issues (comparable to stating the research problem), some entries serve to outline treatment plans or strategies (hypotheses and experiments), other entries serve to present bits of fact (similar to research notes), while other entries again serve to review what has been learned so far (analysis and interpretation of experiments). Written over time by several clinicians, often from different specialisms, in a highly distributed process, the clinical notes serve to reflect ongoing external developments, select and counterpose bits of data, formulate hypotheses as to causation, suggest lines of action, etc.

\subsection{Modes of discourse}

The physicians make use of different varieties or modes of discourse in the clinical notes, depending on the purpose and type of note being produced.

The principal mode is narrative. Taken together the set of clinical notes constitute a 'reiterative, cumulative manuscript' (Montgomery Hunter 1991), where each new entry interprets, elaborates and extends the previous entries. In this way, the notes recount the story of the patient's illness and medical care, told as it happens. It is an 'eyewitness account,' an unfolding, more-or-less coherent story rich in detail and, 
sometimes, drama and impending tragedy. It is an attempt to make sense of, document and, in Atkinson's (1995) words, 'justify past actions, current understandings and future plans' (p. 90).

Embedded within the narrative are descriptive passages, often in the form of enumerations of observations or laboratory values. A typical example is the systematic review of organ systems included in the ICU admission note from May 27 (see section 4.2 and appendix B). These descriptions are static, but located in time in the sense that they relate to the 'state of the world' at a given point in time.

However, as pointed out in the previous section, the clinical notes are not only used to 'document' and 'justify' the patient's care, they are also, and equally important, used to raise questions, formulate hypotheses, make arguments and draw conclusions. So, one also finds text passages written in what we might call an argumentative mode. In contrast to both the narrative and the descriptive mode, this is an atemporal mode of discourse, which focuses on facts, propositions, and arguments.

For instance, consider this excerpt from a consult note dictated by a hepatologist at Rigshospitalet on 15 June. The reason the hepatologist has been called in is that the ICU physicians have noted increased levels of liver enzymes and suspect this could be an adverse effect of the Cordarone tablets Mads Jensen is taking.

\subsubsection{Hepatological consultation}

consultation requested because of recently developed liver problems.

[...]

During hospitalization newly diagnosed diabetes. Pt is now being treated with Amaryl and insulin therapy .

Pt has no liver related complaints. Since 5.6 roughly normal liver digits with ALT 19, alkaline phospathase 129 and bilirubin 18 . Not possible to assess INR due to anticoagulation therapy. The digits have changed during the hospitalization so that ALT now is around 100, alkaline phospathase around 200, bilirubin still normal. Amylase persistently slightly elevated.

There is suspicion of hepatotoxicity caused by Cordarone. Has been on Cordarone therapy since 2005.

\section{Objective:}

Awake, clear-headed. Unaffected. In good general condition. No cirrhosis stigmata.

Abd.: soft, non-distended, non-tender. No hepatosplenomegaly. No detectable ascites.

\section{Conclusion:}

Regarding the cause of the liver problems, it is most probable that it is a liver reaction to a complicated course of disease. The 


\begin{abstract}
clinical picture could also be due to liver stasis. However, it is less likely that it is a case of Cordarone toxicity, because the pt has tolerated the drug for 3 years. Finally, one ought to rule out chronic viral hepatitis, just as one should consider that the pt could have a nonalcoholic steatohepatitis caused by his diabetes.

$[\ldots]$
\end{abstract}

The hepatologist starts by laying out the relevant facts: The patient has been diagnosed with diabetes during his hospitalization; he has no liver-related complaints; but he has somewhat elevated liver enzymes (ALT, alkaline phospathase) and bilirubin and slightly increased blood levels of amylase. The physical examination shows no signs of liver disease (no cirrhosis stigmata, no hepatosplenomegaly, no ascites). From these premises, she proceeds to discuss possible causes of the observed elevation of liver enzymes, starting from the most likely hypothesis: (1) 'a liver reaction on top of a complicated course of disease' (2) stasis/congested liver (often caused by heart failure), (3) Cordarone toxicity, (4) viral hepatitis, and (5) non-alcoholic steatohepatitis caused by his diabetes. She does not reach a final conclusion, but she finds a Cordarone side effect "unlikely" since he has 'tolerated the medication for 3 years.'

Another example is the consult note from 29 May (presented in Section 4.2) in which the cardiologist formulates and discusses several hypotheses for the cause of the patient's cardiac arrest. Several other examples can be found in the notes.

In other words, it would be misleading to say that clinical notes are entirely narrative in form, as is often assumed, or implied, by researchers of medical knowledge and medical work (e.g., Poirier and Brauner, 1990; Montgomery Hunter, 1991; Atkinson, 1995; Kay and Purves, 1996; Mattingly, 1998a, b; Hobbs, 2003). On the contrary, as we have shown, the clinical notes genre allows not only for variations in format and detail, but also for the flexible combination of different modes of discourse, notably narrative and argumentative, dependent on the task at hand.

\title{
5.4. Uncertainty and the expression of degrees of trust
}

It is characteristic of the clinical notes we have analyzed that doubt, uncertainty, and ambiguity are very much present in them. Physicians must regularly act upon uncertain, incomplete, and even contradictory evidence, and the process of diagnosis and treatment is therefore, in the words of Poirier and Brauner, often 'fraught with ambiguity and inconclusiveness' (1990, p. 31).

This essential uncertainty of medical practice is reflected in the physicians' narration. For instance, in his discussion of case presentations among haematologists, Atkinson (1995) remarks:

The medical practitioner must speak about and act on knowledge which has various kinds of warrant, and of which the speaker has differing degrees of firsthand 
experience. [...] In formulating an account of the case, therefore, the physician does not merely collate knowledge and information, facts and opinion. He or she construct narratives and opinions which reflect different attitudes towards that knowledge: degrees of trust are expressed; credibility and plausibility of other's accounts are made available to an audience of peers; one's personal interpretations and recommendations are couched in situationally appropriate terms. (Atkinson, 1995, p. 117).

Consequently, the rhetoric of medical discourse is characterized by a 'rich situated vocabulary' and 'complex and delicate expressions and codings of knowledge and opinion' (Atkinson, 1995, p. 117). In what follows we examine examples, drawn from the medical record of Mads Jensen, that illustrate and develop this point.

First of all, we note that the physicians are wary of drawing unfounded or premature conclusions about the source of the patient's problems and that they, therefore, often present their hypotheses and conclusions as tentative and provisional. A good example is the cardiologist's note from 29 May (see the previous section), where he is considering two possible causes of the patient's sudden heart arrest (an acute Amiodarone effect or an acute ischemic heart failure):

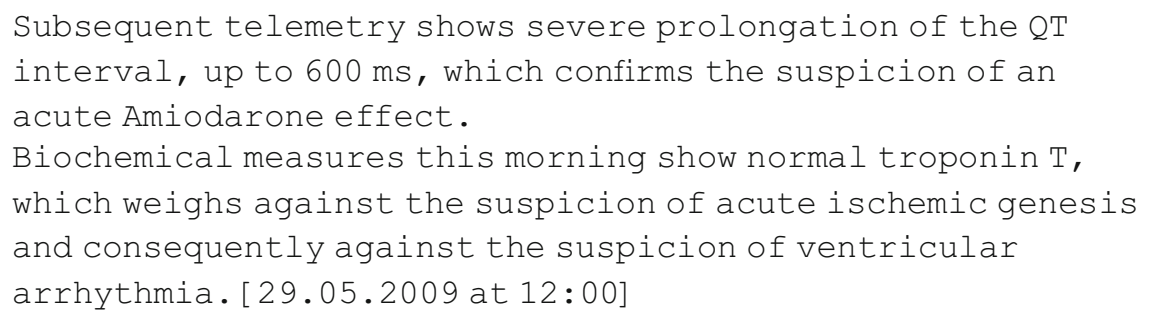

He presents the two competing hypotheses and discusses the evidence for and against each of them. Careful in this choice of words, he talks about 'suspicions' and evidence that 'confirms' or 'weighs against' such suspicions, and he refrains from drawing any firm conclusions at this point. Instead, he concludes that the 'most probable' diagnosis is 'paroxystic atrial fibrillation and atrial flutter that despite Cordarone are being conducted with a high rate to the ventricles'.

There are many other examples where the physicians explicitly share their doubts and uncertainties with the reader, for instance by hedging their statements with adverbs such as 'possibly', 'probably', and 'presumably' and by using phrases such as 'one must suspect', and 'it could be', as illustrated by the following two examples:

One must suspect that the cardiac arrest is caused by arrhythmia. [28.05.2009 at $11: 15]$

Pt has rapidly increasing biochemical markers of infection, possibly stemming from pneumonia

[30.05.2009 at 09:45] 
Hedging refers to the use of words or expressions that makes a statement less forceful or assertive (Atkinson, 1995, p. 117). A hedge is a marker of uncertainty in discourse, typically an adjective or an adverb, but also certain verbs ('suppose', 'appears') and expressions can serve as a hedge. It may mark information as more or less reliable or approximate and allows a speaker/writer to 'explicitly qualify his/her lack of commitment to the truth of a proposition he/she utters' (Crompton, 1997, p. 281).

Secondly, although it is relatively uncommon, there is even room for disagreements in the notes:

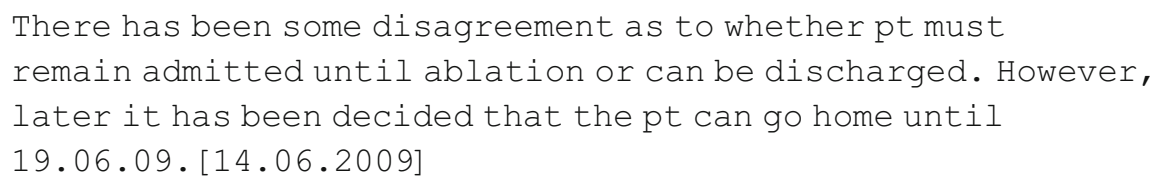

There has been some disagreement as to whether pt must remain admitted until ablation or can be discharged. However, later it has been decided that the pt can go home until $19.06 .09 .[14.06 .2009]$

Finally, the physicians carefully express their degree of trust in the recorded information by marking both the source and status of knowledge (factual, firsthand, or reported) and, sometimes, even by explicitly questioning its trustworthiness. They do so by following writing conventions that link grammatical forms to the sources of information (Hobbs, 2003, p. 472). Basically, they distinguish between three types of information:

(1) Information obtained from the patient or from his or her relatives. The patient's own report of his or her symptoms is marked as indirect discourse:

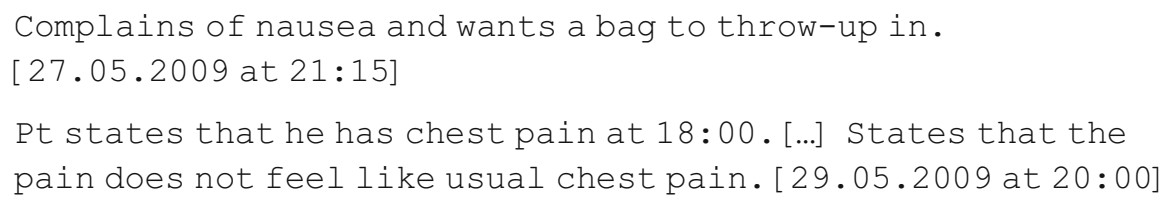

Information that comes from relatives is always explicitly marked for source, as in these examples:

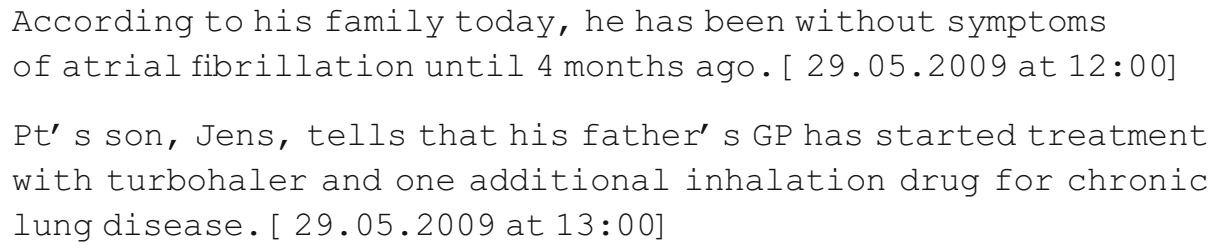

(2) Information that has been reported by other health professionals, either in writing or orally. Conventionally, the physicians use the agentless passive voice (or the Danish 'man', equivalent to the English 'one' in the sense of 'anyone') to convey this type of information, as illustrated by the following examples:

Known with paroxystic atrial fibrillation, treated with ablation in fall 2006. [ 29.05.2009 at 12:00]

One tries immediately conversion with bolus Cordarone $300 \mathrm{mg}$. [02.06.2009] 
The information is not attributed to specific individuals, but the use of the passive voice indicates that it is obtained from other health professionals, rather than from lay people (e.g., patients or relatives). This is in line with Hobbs' observation that 'the passive voice is conventionally and pervasively used in medical notation to record information obtained from the oral or written reports of other treaters' (Hobbs, 2003, p. 465). The statements are typically unmarked and thus treated as unproblematic and uncontested.

(3) Information that is 'deemed to be directly observable or independently verifiable' (Hobbs, 2003, p. 460), often referred to as 'objective data' in the U.S. These include the physician's own observations as well as the results of any diagnostic tests such as blood results, ECG, and X-rays. These data are conventionally reported as 'facts':

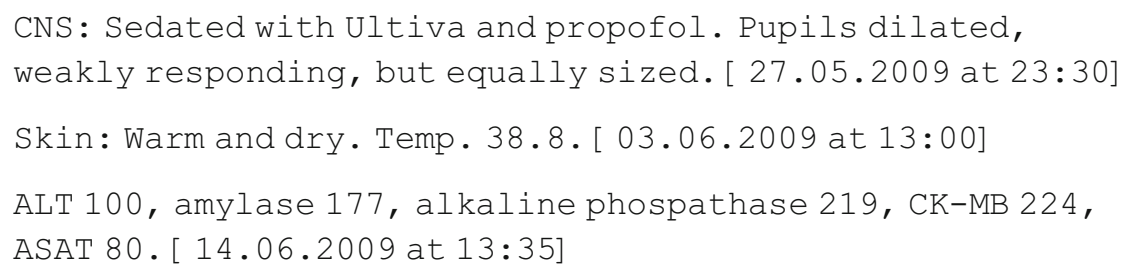

However, even the trustworthiness of this kind of 'objective' data may be disputed. For instance, in one of the notes from 30 May, the ICU physicians doubt the information that the patient has a thrombocyte count of 6 (a very low value) and order a new blood test:

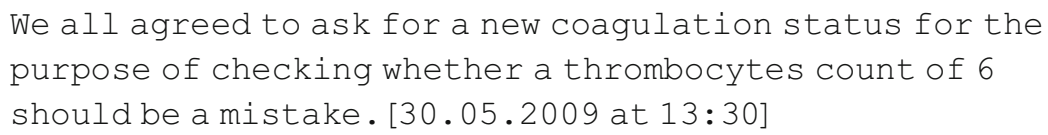

Interestingly, Atkinson (1995, p. 117) reports similar findings from his study of case presentations among haematologists in the UK, and Hobbs (2003) finds virtually the same distinctions and conventions for marking recorded information for both source (patient/relatives, healthcare professionals, or direct evidence) and status of knowledge ('factual' or 'reported') in the clinical notes of an American pediatric resident's notes. This underlines the broad normative scope of the genre within Western medicine.

\section{Discussion}

The clinical notes mediate the integrative discourse in which the ensemble of clinicians collectively make sense of the myriad inscriptions on multitudes of artifacts associated with the medical record and express what they collectively take to be the state of the world at the time of writing. But of course, the clinical notes do not stand alone. They only make sense as part of an ongoing conversation among physicians (and other clinicians) about possible diagnostic and treatment options (Garfinkel and Bittner, 1967; Conn et al., 2009). 


\subsection{The role of clinical notes in medical practice}

As Atkinson (1995) has pointed out, the practice of medicine constitutes to a large extent an oral culture. Physicians constantly talk with each other, with other health professionals, and with patients - in clinical conferences, during ward rounds, in the hallway, by telephone, and so on. Nevertheless, the written clinical notes provide a common point of reference, which is of crucial importance given the highly distributed and around-the-clock nature of hospital work. They serve as the "primary means of communication among treaters who are not co-present with each other' and allow them not only to coordinate their actions but also to share their thoughts and observations concerning diagnosis and treatment (Hobbs, 2003). Thus, according to Atkinson, there is a 'close relationship between [the] written and oral accounts' (Atkinson, 1995, p. 91) of patient care constructed by physicians. Physicians refer to the clinical notes (and other written materials) when discussing the patient with their colleagues and the outcome of these discussions may in turn be recorded in subsequent clinical notes. Several examples of this are present in Mads Jensen's medical record.

As we have shown in the previous sections, clinical notes are far from being idiosyncratic scribbles or 'glob[s] of free text' as one medical informatics researcher disdainfully has put it (McDonald, 1997, p. 219). On the contrary, they constitute a well-defined genre, with elaborate rules for composing different kinds of notes (e.g., admission notes) and for conveying attitudes towards recorded information (e.g., degree of reliability). This is not to say that there is no variation in how different physicians dictate their notes. Although genres shape communicative action in organizations, genre rules are not rigid and they do not create a 'binding constraint' on the substance and form of the clinical notes (Yates and Orlikowski, 1992, p. 306). As we have seen, the genre rules are flexible enough to allow for significant and systematic differences in both content and structure of clinical notes from one type of note to the next and from one specialism to another. Furthermore, there are also individual variations in how physicians dictate their notes, and the rules can always be bent or broken, depending on the circumstances and on the information the physician may wish to convey.

Nevertheless, clinical notes have their own distinctive format and style that enable experienced physicians to exchange information and thoughts efficiently. The genre rules guide authors in composing notes and they orient readers to how they should be read and what they should look for and expect to find where. Thus, in a study of physicians' ways of reading medical records, Nygren and Henriksson found that the 'format, layout and other textural features' provided 'effective guidance in the process of searching, reading and assessing the relevance of different items of information in the record' and allowed them to skim through even quite voluminous notes rather easily $(1992$, p. 1$) .^{21}$

\footnotetext{
${ }^{21}$ The study did not focus exclusively on the clinical notes, but on the traditional medical record as a whole, that is, including lab reports, X-rays, etc. contained in the patient's folder.
} 
This is presumably not just because the conventions of the genre impose a certain degree of standardization, but also because they promote an 'economy of form' (Hobbs, 2003, p. 471) without superfluous details or explanations, which allows physicians to convey a great deal of information in a few words. As pointed out previously, the notes constitute what Hobbs (2003) refers to as a 'condensed text', which relies on the reader's background knowledge and ability to 'read between the lines' in order to decode the meaning of the text. Physicians share vast amounts of medical knowledge and they rely heavily on this background knowledge when dictating and reading clinical notes:

Background knowledge operates as a reciprocally shared resource, with speakers assuming its availability to recipients in designing their utterances, and recipients assuming that this assumption has in fact been made, and interpreting the message accordingly. (Hobbs, 2002, p. 267).

However, it is important to recognize that although all physicians share a great deal of medical knowledge, there is also much medical knowledge that only belongs to certain groups of specialists. In other words, physicians from different specialisms constitute separate communities of practice and as a consequence physicians from different specialisms may have trouble understanding each others' clinical notes (Bansler et al 2010).

The clinical notes document the 'core narrative' of the patient's illness and medical care (Kay and Purves, 1996; Hobbs, 2003). It is not the patient's story, but a medical narrative, authored collectively by the physicians as part of their effort to diagnose and treat the patient's illness:

The medical record contains the medical discourse of at least one physician talking, so to speak, to him- or herself about the possibilities of diagnosis and treatment, a process which can be fraught with ambiguity and inconclusiveness. (Poirier and Brauner, 1990, p. 31).

The medical narrative reflects not only the bias of the medical specialism, but also the bias of its individual authors (Montgomery Hunter, 1992) and in this sense it is always incomplete and limited. It cannot be otherwise. The construction of a narrative necessarily implies a selection and ordering process (Weick, 1995), and this can only be done from a certain perspective and for a specific purpose. The physician sifts through the available evidence in the form of the patient's own account of the course of illness, the results from the physical examination, lab data, $\mathrm{X}$-rays, pathology reports, etc., assesses its credibility, identifies important 'events', 'signs', and 'symptoms', and arranges them in a certain order to construct a recognizable medical narrative. The function of the narrative is to give meaning to a vast, but usually also incomplete, inconsistent, and even contradictory, collection of raw data by creating tentative causal relations between selected events, signs, and 
symptoms, thereby allowing these to 'take their meaning by belonging to, and contributing to, the story as a whole' (Mattingly, 1998b, p. 46). The structure of the narrative serves to:

emphasize or de-emphasize certain story-events, to interpret some and to leave others to inference, to show or to tell, to comment or to remain silent, to focus on this or that aspect of an event or character. (King 1992, cited by Kay and Purves, 1996, p. 76).

In sum, clinical notes are not a complete or literal recording of the patient's illness trajectory, but rather a highly selective account of events, findings, and thoughts, constructed in search for a plausible causal chain of events which could explain the patient's condition and provide a basis for action. They function as a cognitive artifact that facilitates memory and recall and they enable collective sensemaking and coordination of actions in a highly complex, distributed work practice.

\subsection{Implications for the EMR}

Before we turn to the issue of how to incorporate clinical documentation into the EMR, it is first necessary to realize that 'business as usual' is not an option, because current coordinative practices based on the traditional paper-based medical record are not sustainable. The medical record was created at a time when the division of labor in medicine was less developed and typical illness trajectories were shorter and less complicated. Thus, originally, the record was primarily meant to support communication and collaboration within small, relatively homogeneous groups of physicians for a comparatively short period of time. However, as Reiser (1991b) notes, already 'in the early 20th century, the data in the medical record were beginning to burst the confines of the form' as 'medical technology advanced and specialization increased' (p. 982).

This problem is, of course, dramatically exacerbated in the health care system of today. Patients with multiple chronic diseases often have complicated, protracted courses of illness and require treatment from numerous medical specialties (e.g., cardiology, cardiovascular surgery, endocrinology, gastroenterology, neurology, and geriatrics). The result is that a typical patient's medical record may span years or even decades, contain hundreds of lab reports, images, diagrams, forms and other documents as well as clinical notes from various medical experts, and be physically distributed over several locations. When the paper record swells to such proportions, it becomes quite unmanageable, fragmented and nearly impossible to browse, read, and absorb in any meaningful way.

\subsection{1. 'Structured data' versus clinical narratives}

The idea of an EMR system is fraught with serious difficulties simply because the medical record is not just any organizational record. EMR systems must serve many divergent purposes and interests, both clinical (medical reasoning and decision 
making, communication and coordination among clinicians) and administrative (billing and reimbursement, quality assurance, resource planning, accreditation, etc.).

However, as pointed out already 50 years ago by Harold Garfinkel and Egon Bittner, in their study of psychiatric records, administrative and clinical records are organized by entirely different kinds of logic. In an administrative record system 'information may be repeated for the sake of expediency', because 'the statement of a present state of a bank account does not add any information to what can be readily gathered from the account's earlier state and the subsequent deposits and withdrawals': 'If the two do not match, this points irrefutably to some omission. The record is governed by a principle of relevance with the use of which the reader can assess its completeness and adequacy at a glance'. In contrast, a clinical record works in a different way:

A subsequent entry may be played off against a former one in such a way that what was known then, now changes complexion. The contents of a folder may jostle each other in bidding to play a part in a pending argument. It is an open question whether things said twice are repetitions, or whether the latter has the significance, say, of confirming the former. The same is true of omissions. Indeed, both come to view only in the context of some elected scheme of interpretation. (Garfinkel and Bittner, 1967, pp. 204-205).

Given this observation, it is not surprising that how to integrate clinical documentation into the EMR has proven to be a difficult and controversial issue that has attracted much attention of researchers as well as managers, administrators and clinicians. As of the 1990s, researchers within the field of medical informatics have been working hard at 'taming' and 'domesticating' physicians' clinical notes (McDonald, 1997, p. 219) by replacing them with codes or 'structured data' (Rosenbloom et al., 2010; Rosenbloom et al., 2011). They have promoted the use of 'structured data entry' where the physician enters data by selecting from a list of predefined medical concepts and typing values into fields (Bleeker et al., 2006; Rosenbloom et al., 2011). The aim being to generate standardized data that can be reused for secondary purposes such as clinical research, quality assessment, decision support, resource allocation, and - last but not least - billing.

However, clinicians have generally been opposed to this. They find it timeconsuming and error prone to input data by clicking radio buttons, selecting clinical concepts from pop-up menus, or searching long lists of controlled vocabularies for the right term to use (Powsner et al., 1998; Walsh, 2004; Khorana, 2010; Lewis, 2011). A recent policy paper from the American College of Physicians summarizes the criticism in the following way:

The act of entering coded observations into a record, such as by selecting items from a list, is slow and awkward by nature. The mental activity involved in converting a patient narrative into coded values on a highly structured screen can lead to errors. Documentation of these types of clinical information via drop-down lists, check 
boxes, macros, and templates can be distracting to the physician and disruptive to vital clinical thinking and storytelling. These data capture features, when used in excess, can undermine the value of the information by standardizing away the heterogeneity that makes each patient encounter unique. (Kuhn et al., 2015).

In other words, as pointed out by Rosenbloom et al (2011), there is an essential 'tension' between the clinicians' needs for concise and nuanced documentation and the needs of those who want to reuse data from the EMR for secondary purposes such as billing and reimbursement, quality assurance, resource planning, and clinical research. Clinicians generally value efficiency, flexibility, and narrative expressivity while those reusing data cherish structure and standardization (Winthereik and Vikkelsø, 2005; Rosenbloom et al 2011).

Our study strongly supports the clinicians' view that flexibility and expressivity are of the utmost importance. To be truly useful in clinical practice, EMR systems must accommodate physicians' need for composing, storing and sharing medical narratives in a straightforward and flexible way. The richness and nuance of the clinical notes, including their ability to deal with ambiguous and contradictory information, can in no way be replaced with 'structured data' and 'codes' without compromising patient safety and quality of care.

\subsubsection{In lieu of a conclusion}

It is becoming increasingly clear that there are fundamental problems in the way current EMR systems handle clinical data capture and documentation and that they are not easily solvable. There is no quick fix or easy solution, because the problems stem both from the tension between clinical and administrative needs and from a basic lack of understanding of the role of documentation in medical practice as related to the complexities of clinical collaboration, discourse, and reasoning.

Current approaches to EMR design threaten to undermine the whole project, driven as they seem to be by an excessive emphasis on generating high-quality 'structured' data for secondary purposes - billing, quality assurance, research, etc. at the expense of actually supporting clinicians in their daily work. There is a strong risk that this will lead to widespread dissatisfaction among clinicians and an increased reliance on unofficial parallel forms of documentation (Park et al., 2013), sometimes referred to as 'shadow charts' (Wears 2008) or 'parallel charts' (Siegler and Adelman, 2009). The consequence may be that important information never becomes reflected in the formal medical record, but only in these unofficial documents. This practice, of course, risks seriously compromising patient safety, quality of care, and, ironically, the quality of data for secondary uses.

To rectify this situation, EMR designers must first and foremost focus on clinicians' documentation needs and emphasize the ability of EMR systems to facilitate flexible, convenient, and efficient documentation practices. One option would, for instance, be to drop the idea of 'structured data entry' and instead let physicians continue using dictation with transcription or speech-recognition software, and then 
use natural language processing (NLP) post hoc to generate structured data for secondary purposes. However, it is not clear whether or not such a solution would actually be useful and feasible. There is simply still too much we do not know about clinical documentation practices and too many open questions about how best to incorporate medical narratives in the EMR. Although the paper-based clinical notes genre is widespread today, it is difficult to see what the electronic equivalent should look like and what exactly its role should be in relation to the structured or coded data in the record. Consequently, there is a strong need for more field-based innovation and experimentation to develop and test new approaches to the design of EMR systems.

\section{Acknowledgment}

The contributions of the technicians and cardiologists who supported the project are gratefully acknowledged. The research reported in this article was carried out as part of the 'Co-constructing IT and Health' (CITH) project funded by the Danish Council for Strategic Research (Grant \#2106-07-0017).

Open Access This article is distributed under the terms of the Creative Commons Attribution 4.0 International License (http://creativecommons.org/licenses/by/4.0/), which permits unrestricted use, distribution, and reproduction in any medium, provided you give appropriate credit to the original author(s) and the source, provide a link to the Creative Commons license, and indicate if changes were made.

\section{Appendix A - List of abbreviations used in the notes}

$\begin{array}{ll}\text { Abd } & \text { Abdomen } \\ \text { ABG } & \text { Arterial Blood Gas (a blood test) } \\ \text { AF } & \text { Atrial Fibrillation } \\ \text { AFib } & \text { Atrial Fibrillation } \\ \text { ALS } & \text { Advanded Life Support } \\ \text { ALT } & \text { Alanine Transaminase (a liver enzyme) } \\ \text { BE } & \text { Base Excess (the loss of buffer base to neutralize acid) } \\ \text { BP } & \text { Blood Pressure } \\ \text { BPM } & \text { Beats Per Minute } \\ \text { CAG } & \text { Coronary Arteriography } \\ \text { CK-MB } & \text { Creatine Kinase-MB (an enzyme) } \\ \text { CNS } & \text { Central Nervous System } \\ \text { Coag. } & \text { Coagulation } \\ \text { CVC } & \text { Central Venous Catheter } \\ \text { CVS } & \text { Cardiovascular System } \\ \text { CWARD } & \text { The cardiology department (a pseudonym) } \\ \text { DC } & \text { Direct Current (cardioversion) } \\ \text { D-dimer } & \text { A fibrin degradation product (or FDP), a small protein fragment present in the blood after } \\ & \text { a blood clot is degraded by fibrinolysis }\end{array}$




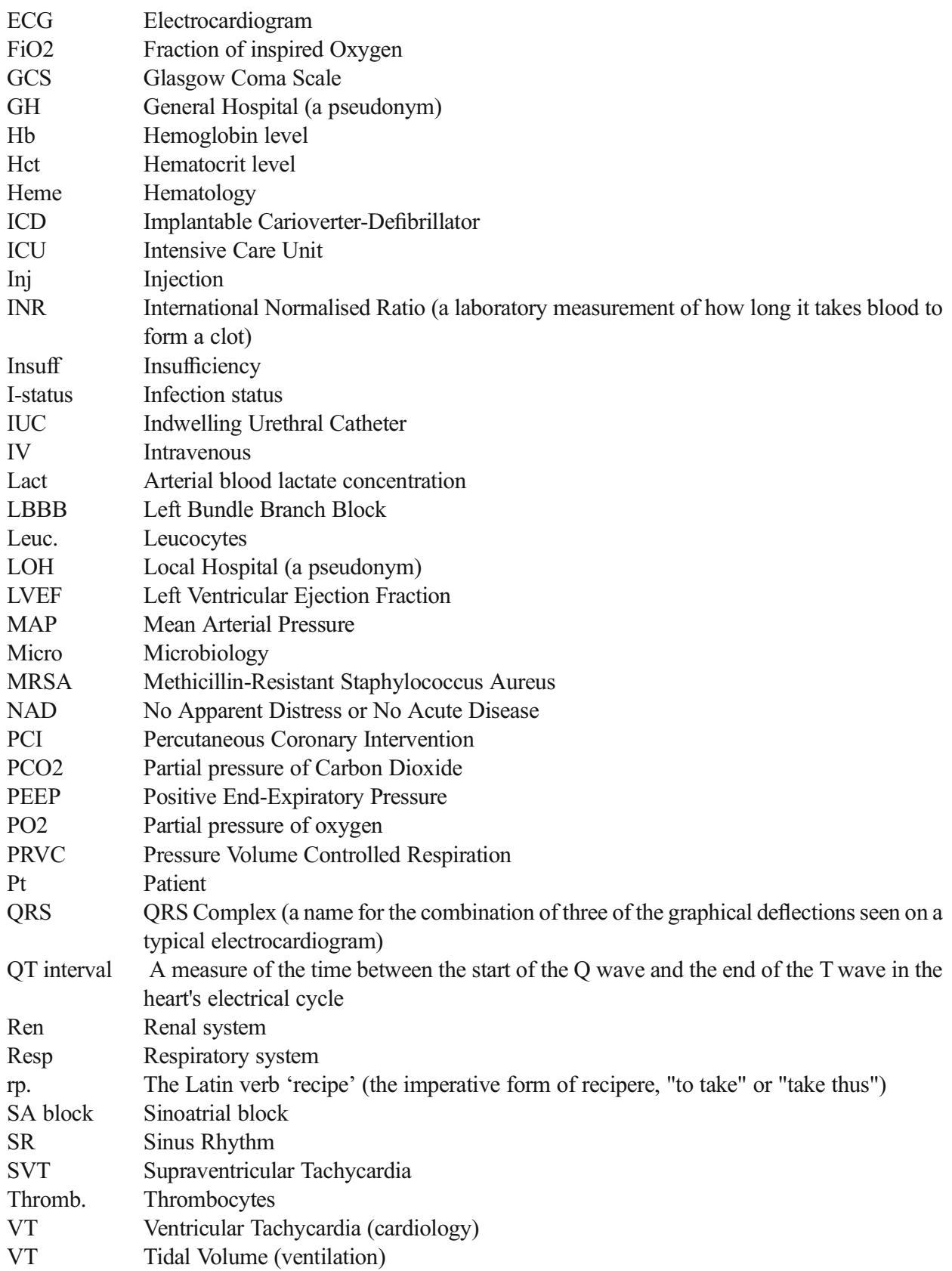




\section{Appendix B - Example of admission note}

\subsubsection{3:30 ZWARD}

\section{Admission ward z}

65-year-old male transferred from Y21 after witnessed cardiac arrest and resuscitation.

\section{Allergies}

None known.

\section{Exposures}

None for MRSA.

\section{Previous}

Paroxystic AFib for several years.

Ablation 2005.

Angina.

\section{Medicine}

Simvastatin $40 \mathrm{mg} \times 1$.

Isoptin R $120 \mathrm{mg} \times 1$.

Imdur $30 \mathrm{mg} \times 2$.

Marevan according to schedule.

Cordarone $200 \mathrm{mg} \times 1$.

\section{Alcohol}

Nihil.

\section{Tobacco}

3 daily.

\section{Present}

Pt admitted tonight by ambulance due to AF with $1: 1$

conduction. General condition affected by this. In addition dilated unresponsive pupils observed. In the admission room at C 23, Cordarone is given and pt becomes momentarily unresponsive, has generalized tonic-clonic seizures and goes into clinical cardiac arrest. In the beginning what looks like VT, but before we get to give a shock, then asystole. Chest compressions and ventilation is started and atropine $3 \mathrm{mg}$ and adrenalin $1+1 \mathrm{mg}$ are administered. Pt is intubated. After 6 min. of ALS pt has spontaneous circulation again. GCS 3. Gets intermittent jerks, is grimacing on the tube and increases to GCS 6. First ABG with pH 6.92, PCO2 9.21, PO2 10.1, BE 16.9, lact. 9.5. Infusion with bicarbonate $100 \mathrm{ml}$. is administered. Transferred to ICU, where cooling, sedation is commenced. Bladder catheter and an arterial line are inserted and a 5- 
lumen CVC is placed in the right-sided external jugular vein (right side due to marevan).

CNS: Sedated with Ultiva and propofol. Pupils dilated, weakly responding, but equally sized.

No sign of a stiff neck. Babinski neg. Patellar and biceps

reflexes without response.

Resp: Oral Tube. PRVC, VT $420 \mathrm{ml}$, PEEP 10, FiO2 100 \%

Lungs: NAD.

Heart: ECG with SR and LBBB (previously known). MAP 74 .

Heart auscultation: NAD

Abd: Soft, no reaction to palpation. Bowel sounds normal.

Ren: IUC. Reduced urine flow. Purulent secretion from penis.

K 3, 9, Na 141 .

Heme: Hb 8, 4, Het 41, 5 .

Micro: Leukocytes 18 .

\section{Assessment}

Resuscitated cardiac arrest patient with unknown genesis of the cardiac arrest.

Sedated, cooled and cardiovascularly and respiratorily stable.

\section{Plan}

Re CNS :

Re Resp:

Aim at

Re CVS :

and

\begin{tabular}{|c|c|}
\hline rp. & sedation \\
\hline rp. & cooling for $12-24$ hours \\
\hline$r p$ & $\begin{array}{l}x-r a y \text { thorax } \\
\mathrm{PO} 2>9, \quad \mathrm{PCO} 2<7\end{array}$ \\
\hline rp. & $\begin{array}{l}\text { coronary enzymes } \\
\text { ECG at times } 0,6,12,18,24 \\
\quad \text { hours }\end{array}$ \\
\hline rp. & D-dimer \\
\hline - & $\begin{array}{l}\text { MAP }>65 \\
\text { pause Isoptin } R\end{array}$ \\
\hline
\end{tabular}

\begin{tabular}{|c|c|c|}
\hline Re Abd: & rp. & parenteral nutrition \\
\hline & rp. & insulin inj. cf. instructions \\
\hline & rp. & Pantotrapzol \\
\hline Re Ren: Aim at & rp. & $\begin{array}{l}\text { Urine production per hour }>1 \\
\mathrm{ml} / \mathrm{h} \text { by volume therapy }\end{array}$ \\
\hline Aim at & & K 4.0 \\
\hline Re Microbiol.: & rp. & cultivation incl. urethra \\
\hline & rp. & cefuroxim \\
\hline In addition & rp. & $\begin{array}{l}\text { Mg and } P \text { at times } 0,12,24, \\
36 \text { and } 48 \text { hours }\end{array}$ \\
\hline & rp. & $\begin{array}{c}\text { I-status, liver + coag. counts } \\
\text { John Andersen }\end{array}$ \\
\hline
\end{tabular}




\section{References}

Andersen, Tariq; Jørgen P. Bansler; Finn Kensing; Jonas Moll; and Karen Dam Nielsen (2014). Alignment of concerns: A design rationale for patient participation in eHealth. In R. H. Sprague, Jr. (ed.): HICSS 2014: Proceedings of the 47th Hawaii International Conference on System Science, 6-9 January 2014, Hawaii. Los Alamitos, Calif., etc.: IEEE Computer Society Press, pp. 25872596

Atkinson, Paul (1995). Medical Talk and Medical Work: The Liturgy of the Clinic. London, etc.: SAGE Publications

Bansler, Jørgen P.; Erling C. Havn; and Troels Mønsted (2010). Designing shared electronic records for chronic care. In C. Nøhr and J. E. C. M. Aarts (eds.): ITHC 2010: Information Technology in Healthcare: Sociotechnical Approaches, Aalborg, Denmark, 23-24 June 2010. Amsterdam: IOS Press, pp. 53-58.

Bansler, Jørgen P.; and Finn Kensing (2010). Information infrastructures for health care: Connecting practices across institutional and professional boundaries. Computer Supported Cooperative Work (CSCW). Vol. 19, no. 6, December 2010, pp. 519-520.

Bansler, Jørgen P.; Erling C. Havn; Troels Mønsted; and Kjeld Schmidt (2011). A study of the fragmentation of the medical record. In P. Bjørn; F. Kensing; and L. R. Christensen (eds.): Infrastructures for Healthcare 2011: Global Healthcare: Proceedings of the 3rd International Workshop, 23-24 June 2011, Copenhagen. Copenhagen: IT University of Copenhagen, pp. 94-97.

Bansler, Jørgen P.; Erling C. Havn; Troels Mønsted; Kjeld Schmidt; and Jesper Hastrup Svendsen (2013a). Physicians' progress notes: The integrative core of the medical record. In O. W. Bertelsen, et al. (eds.): ECSCW 2013: Proceedings of the 13th European Conference on Computer-Supported Cooperative Work, 21-25 September, Paphos, Cyprus. London: Springer, pp. 123-142.

Bansler, Jørgen P.; Erling C. Havn; Troels Mønsted; and Kjeld Schmidt (2013b). At the center of the galaxy: The integrative role of medical progress notes. In G. Ellingsen and P. Bjørn (eds.): InfraHealth 2013: The 4th international workshop on Infrastructures for Healthcare: Action Research, Interventions, and Participatory Design, 13-14 June 2013, Tromsø, Norway.

Bardram, Jakob E.; and Claus Bossen (2005). A web of coordinative artifacts: collaborative work at a hospital ward. In K. Schmidt, et al. (eds.): GROUP'05: International Conference on Supporting Group Work, 6-9 November 2005, Sanibel Island, Florida. New York: ACM Press, pp. 168-176.

Berg, Marc (1992). The construction of medical disposals: Medical sociology and medical problem solving in clinical practice. Sociology of Health \& Illness. Vol. 14, no. 2, June 1992, pp. 151-180.

Berg, Mark; and Geoffrey Bowker (1997). The multiple bodies of the medical record: Towards a sociology of an artifact. Sociological Quarterly. Vol. 38, no. 3, June 1997, pp. 511-535.

Bleeker, Sacha E.; Gerarda Derksen-Lubsen; Astrid M. van Ginneken; Johan Van Der Lei; and Henriëtte A. Moll (2006). Structured data entry for narrative data in a broad specialty: Patient history and physical examination in pediatrics. BMC medical informatics and decision making. Vol. 6, no. 1, July 2006, p. Article 29.

Bossen, Claus (2006). Representations at work: A national standard for electronic health records. In P. J. Hinds, et al. (eds.): CSCW 2006: ACM Conference on Computer Supported Cooperative Work, 4-8 November 2006, Banff, Alberta, Canada. New York: ACM Press, pp. 69-78.

Bossen, Claus; and Lotte Groth Jensen (2014). How physicians "achieve overview": A case-based study in a hospital ward. In S. Fussell, et al. (eds.): CSCW 2014: Proceedings of the 17th ACM 2014 Conference on Computer Supported Cooperative Work and Social Computing, Baltimore, Maryland, 15-19 February 2014. New York: ACM Press, pp. 257-268.

Bruner, Jerome Seymour (1991). The narrative construction of reality. Critical Inquiry. Vol. 18, no. 1, Autumn 1991, pp. 1-21.

Car, Josip, et al. (2008a). The Impact of eHealth on the Quality and Safety of Healthcare: A Systemic Overview \& Synthesis of the Literature: Report for the NHS Connecting for Health Evaluation Programme. University of Edinburgh, March 2008. 
Car, Josip, et al. (2008b). The Impact of eHealth on the Quality and Safety of Healthcare: A Systemic Overview \& Synthesis of the Literature: Report for the NHS Connecting for Health Evaluation Programme: Extended Executive Summary. University of Edinburgh, March 2008.

Conn, Lesley Gotlib, et al. (2009). Communication channels in general internal medicine: Adescription of baseline patterns for improved interprofessional collaboration. Qualitative Health Research. Vol. 19, no. 7, July 2009, pp. 943-953

Craig, Barbara Lazenby (1989-90). Hospital records and record-keeping, c. 1850 - c. 1950: Part I: The development of records in hospitals. Archivaria. Vol. 29, Winter 1989-90, pp. 57-87.

Craig, Barbara Lazenby (1990). Hospital records and record-keeping, c. $1850-c .1950$ : Part II: The development of record-keeping in hospitals. Archivaria. Vol. 30, Summer 1990, pp. 21-38.

Crompton, Peter (1997). Hedging in academic writing: Some theoretical problems. English for Specific Purposes. Vol. 16, no. 4, December 1997, pp. 271-287.

Davenport, Nancy H. M. (2011). Medical residents' use of narrative templates in storytelling and diagnosis. Social Science \& Medicine. Vol. 73, no. 6, September 2011, pp. 873-881.

Fitzpatrick, Geraldine (2004). Integrated care and the working record. Health Informatics Journal. Vol. 10, no. 4, December 2004, pp. 291-302.

Fitzpatrick, Geraldine; and Gunnar Ellingsen (2013). A review of 25 years of CSCW research in healthcare: Contributions, challenges and future agendas. Computer Supported Cooperative Work (CSCW). Vol. 22, no. 4-6, August-December 2013, pp. 609-665.

Garfinkel, Harold; and Egon Bittner (1967). "Good" organizational reasons for "bad" clinic records. In H. Garfinkel: Studies in Ethnomethodology. Englewood-Cliffs, New Jersey: Prentice-Hall 1967, pp. 186-207.

Greenhalgh, Trisha; Henry W. W. Potts; Geoff Wong; Pippa Bark; and Deborah Swinglehurst (2009). Tensions and paradoxes in Electronic Patient Record research: A systematic literature review using the meta-narrative method. The Milbank Quarterly. Vol. 87, no. 4, December 2009, pp. 729-788

Hartswood, Mark; Rob Procter; Mark Rouncefield; and Roger Slack (2003). Making a case in medical work: Implications for the electronic medical record. Computer Supported Cooperative Work (CSCW). Vol. 12, no. 3, September 2003, pp. 241-266.

Hewett, David G.; Bernadette M. Watson; Cindy Gallois; Michael Ward; and Barbara A. Leggett (2009). Communication in medical records: Intergroup language and patient care. Journal of Language and Social Psychology. Vol. 28, no. 2, June 2009, pp. 119-138.

Hobbs, Pamela (2002). Islands in a string: The use of background knowledge in an obstetrical resident's notes. Journal of Sociolinguistics. Vol. 6, no. 2, May 2002, pp. 267-274.

Hobbs, Pamela (2003). The use of evidentiality in physicians' progress notes. Discourse Studies. Vol. 5, no. 4, November 2003, pp. 451-478.

Irwin, Richard S.; and James M. Rippe (2008). ntensive Care Medicine. Philadelphia: Lippincott Williams \& Wilkins. (6th ed.).

Kassell, Lauren (2014). Casebooks in early modern England: Medicine, astrology, and written records. Bulletin of the History of Medicine. Vol. 88, no. 4, Winter 2014, pp. 595-625.

Kay, S.; and I. N. Purves (1996). Medical records and other stories: A narratological framework. Methods of Information in Medicine. Vol. 35, no. 2, June 1996, pp. 72-87.

Khorana, Alok A. (2010). Physician as typist. Journal of Clinical Oncology. Vol. 28, no. 24, 20 August 2010, pp. 3899-3900

Kuhn, Thomson; Peter Basch; Michael Barr; and Thomas Yackel (2015). Clinical documentation in the 21st century: Executive summary of a policy position paper from the American College of Physicians. Annals of Internal Medicine. Vol. 162, no. 4, 17 February 2015, pp. 301-303

Larsen, Peter (2013). Mediated fiction. In K. B. Jensen (ed.): A Handbook of Media and Communication Research: Qualitative and Quantitative Methodologies. Milton Park, UK: Routledge, pp. 117-137. 
Leder, Drew (1990). Clinical interpretation: The hermeneutics of medicine. Theoretical Medicine. Vol. 11, no. 1, March 1990, pp. 9-24

Lewis, Stuart (2011). Brave new EMR. Annals of Internal Medicine. Vol. 154, no. 5, 1 March 2011, pp. 368-369

Lock, James D. (1990). Some aspects of medical hermeneutics: The role of dialectic and narrative. Theoretical Medicine. Vol. 11, no. 1, March 1990, pp. 41-49

Loudon, Irvine (1985). The nature of provincial medical practice in eighteenth-century England. Medical History. Vol. 29, no. 1, January 1985, pp. 1-32

Mattingly, Cheryl (1998a). Healing Dramas and Clinical Plots: The Narrative Structure of Experience. Cambridge: Cambridge University Press.

Mattingly, Cheryl (1998b). In search of the good: Narrative reasoning in clinical practice. Medical Anthropology Quarterly. Vol. 12, no. 3, September 1998, pp. 273-297.

McConaghey, R. M. S. (1960). Medical records of Dartmouth, 1425-1887: A contribution to the history of medical practice. Medical History. Vol. 4, no. 2, April 1960, pp. 91-111.

McDonald, Clement J. (1997). The barriers to electronic medical record systems and how to overcome them. Journal of the American Medical Informatics Association. Vol. 4, no. 3, May-June 1997, pp. 213-221

Mønsted, Troels; Madhu C. Reddy; and Jørgen P. Bansler (2011). The use of narratives in medical work: A field study of physician-patient consultations. In S. Bødker, et al. (eds.): ECSCW 2011: Proceedings of the 12th European Conference on Computer Supported Cooperative Work, 24-28 September 2011, Aarhus, Denmark. London: Springer, pp. 81-100.

Mønsted, Troels (2015). Keeping distributed care together: Medical summaries reconsidere. In N. Boulos-Rødje, et al. (eds.): ECSCW 2015: Proceedings of the 14th European Conference on Computer-Supported Cooperative Work, 19-23 September 2015, Oslo, Norway. London: Springer, pp. 143-161

Montgomery Hunter, Kathryn (1991). Doctors' Stories: The Narrative Structure of Medical Knowledge. Princeton, New Jersey: Princeton University Press

Montgomery Hunter, Kathryn (1992). Remaking the case. Literature and Medicine. Vol. 11, no. 1, Spring 1992, pp. 163-179

Montgomery Hunter, Kathryn (1996). Narrative, literature, and the clinical exercise of practical reason. The Journal of Medicine and Philosophy. Vol. 21, June 1996, pp. 303-320

Montgomery Hunter, Kathryn [K. Montgomery] (2006). How Doctors Think: Clinical Judgment and the Practice of Medicine. Oxford: Oxford at the Clarendon Press.

Nygren, Else ; and Peter Henriksson (1992). Reading the medical record. I. Analysis of physicians' ways of reading the medical record. Computer Methods and Programs in Biomedicine. Vol. 39, no. 1-2, September-October 1992, pp. 1-12

Orlikowski, Wanda J.; and JoAnne Yates (1994). Genre repertoire: The structuring of communicative practices in organizations. Administrative Science Quarterly. Vol. 39, no. 4, December 1994, pp. 541-574

Parekh, Anand K.; and Mary B. Barton (2010). The challenge of multiple comorbidity for the US health care system. JAMA: The Journal of the American Medical Association. Vol. 303, no. 13, 7 April 2010, pp. 1303-1304.

Park, Sun Young; Katie Pine; and Yunan Chen (2013). Local-universality: Designing EMR to support localized informal documentation practices. In A. Bruckman, et al. (eds.): CSCW 2013: ACM Conference on Computer Supported Cooperative Work, 23-27 February 2013, San Antonio, Texas. New York: ACM Press, pp. 55-66

Poirier, Suzanne; and Daniel J. Brauner (1990). The voices of the medical record. Theoretical Medicine. Vol. 11, no. 1, March 1990, pp. 29-39

Pomata, Gianna (2010). Sharing cases: The Observationes in early modern medicine. Early science and medicine. Vol. 15, no. 3, 2010, pp. 193-236. 
Pomata, Gianna (2014). The medical case narrative: Distant reading of an epistemic genre. Literature and Medicine. Vol. 32, no. 1, Spring 2014, pp. 1-23

Powsner, Seth M.; Jeremy C. Wyatt; and Patricia Wright (1998). Opportunities for and challenges of computerisation. The Lancet. Vol. 352, no. 9140, 14 November 1998, pp. 1617-1622.

Reiser, Stanley J. (1991a). The clinical record in medicine. Part 1: Learning from cases. Annals of Internal Medicine. Vol. 114, no. 10, 15 May 1991, pp. 902-907.

Reiser, Stanley J. (1991b). The clinical record in medicine. Part 2: Reforming content and purpose. Annals of Internal Medicine. Vol. 114, no. 11, 1 June 1991, pp. 980-985.

Rooksby, John; and Stephen Kay (2003). Patient reports as stories of clinical work: Narrative and work in neuroradiology. Methods of Information in Medicine. Vol. 42, 2003, pp. 445-450

Rosenbloom, S. Trent, et al. (2010). Generating clinical notes for electronic health record systems. Applied Clinical Informatics. Vol. 1, no. 3, 21 July 2010, pp. 232-243.

Rosenbloom, S. Trent, et al. (2011). Data from clinical notes: a perspective on the tension between structure and flexible documentation. Journal of the American Medical Informatics Association. Vol. 18, March 2011, pp. 181-186.

Schmidt, Kjeld; Ina Wagner; and Marianne Tolar (2007). Permutations of cooperative work practices: A study of two oncology clinics. In T. Gross, et al. (eds.): GROUP 2007: International Conference on Supporting Group Work, 4-7 November 2007, Sanibel Island, Florida, USA. New York: ACM Press, pp. 1-10.

Schneider, Karin; and Ina Wagner (1992 [1993]). Constructing the "dossier representatif': Computerbased information-sharing in French hospitals. Computer Supported Cooperative Work (CSCW). Vol. 1, no. 4, December 1992 [article dated 1993], pp. 229-253.

Siegler, Eugenia L.; and Ronald Adelman (2009). Copy and paste: A remediable hazard of electronic health records. The American Journal of Medicine. Vol. 122, no. 6, June 2009, pp. 495-496

Siegler, Eugenia L. (2010). The evolving medical record. Annals of Internal Medicine. Vol. 153, no. 10, 16 November 2010, pp. 671-677, W225-W233.

Stead, William W.; and Herbert S. Lin (eds.) (2009). Computational Technology for Effective Health Care: Immediate Steps and Strategic Directions. Washington, D.C.: National Academies Press

Strauss, Anselm L.; Shizuko Y. Fagerhaugh; Barbara Suczek; and Carolyn L. Wiener (1985). Social Organization of Medical Work. Chicago and London: University of Chicago Press

Svenaeus, Fredrik (2000). Hermeneutics of clinical practice: The question of textuality. Theoretical Medicine and Bioethics. Vol. 21, no. 2, April 2000, pp. 171-189.

Svenaeus, Fredrik (2003). Hermeneutics of medicine in the wake of Gadamer: The issue of phronesis. Theoretical Medicine and Bioethics. Vol. 24, no. 5, September 2003, pp. 407-431.

Svenningsen, Signe [S. Vikkelsø] (2004). Den elektroniske patientjournal og medicinsk arbejde. Reorganisering af roller, ansvar og riscici på sygehuse. København: Handelshøjskolens Forlag.

Walsh, Stephen H. (2004). The clinician's perspective on electronic health records and how they can affect patient care. BMJ: British medical journal. Vol. 328, no. 7449, 15 May 2004, pp. 1184-1187.

Waymack, Mark H. (2009). Yearning for certainty and the critique of medicine as "science". Theoretical Medicine and Bioethics. Vol. 30, no. 3, June 2009, pp. 215-229

Weick, Karl E. (1995). Sensemaking in Organizations. Thousand Oaks, Calif, etc.: Sage Publications.

Winthereik, Brit Ross; and Signe Vikkelsø (2005). ICT and integrated care: Some dilemmas of standardising inter-organisational communication. Computer Supported Cooperative Work (CSCW). Vol. 14, no. 1, February 2005, pp. 43-67

Yates, JoAnne; and Wanda J. Orlikowski (1992). Genres of organizational communication: A structurational approach to studying communication and media. The Academy of Management Review. Vol. 17, no. 2, April 1992, pp. 299-326

Yates, JoAnne; and Wanda J. Orlikowski (2002). Genre systems: Structuring interaction through communicative norms. The Journal of Business Communication. Vol. 39, no. 1, January 2002, pp. $13-35$ 